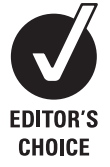

Division of Anatomical Pathology, School of Pathology, University of the Witwatersrand and the National Health Laboratory Service, Johannesburg, Republic of South Africa

Correspondence to:

Professor W Grayson, Suite 308

Private Bag X11, Craighall, 2024,

South Africa;

wayne.grayson@live.com

Accepted 30 October 2007

Published Online First

15 November 2007

\title{
The HIV-positive skin biopsy
}

W Grayson

\section{ABSTRACT}

Dermatological disorders are a frequent presenting feature of HIV infection and/or AIDS. More than $90 \%$ of HIVinfected patients will suffer from one or more skin diseases during the course of their illness. This trend is reflected in the increasing number of skin biopsies from HIV-positive patients in those parts of the world where HIV infection/AIDS is highly prevalent. Histopathologists are therefore required to possess a working knowledge of the broad spectrum of cutaneous manifestations of HIV infection. These include the range of dermatoses that are specific to HIV infection, the more common dermatoses occurring with greater frequency (or modified by) HIV infection/AIDS, the spectrum of infectious diseases (often opportunistic) caused by viruses, bacteria, fungi, protozoa and even arthropods, and neoplastic conditions such as Kaposi sarcoma and B-cell non-Hodgkin lymphoma. The risk for adverse skin reactions to certain drugs is also greatly increased. Although the introduction of highly active antiretroviral therapy has resulted in a dramatic decrease in opportunistic infections, several of these drugs may result in adverse reactions in the skin. Skin biopsies play a vital diagnostic role when different diseases present with clinically similar skin lesions. Biopsy material should always be examined carefully to exclude dual pathology. The diagnosis may need to be confirmed with histochemical and immunohistochemical stains, and/ or molecular studies. Where indicated, additional biopsies for microbiological culture should always be recommended. The examination of multiple serial sections often proves invaluable. A diagnostic approach is given based on the predominant histological reaction pattern, with an emphasis on clinicopathological correlation.

According to the 2006 UNAIDS survey, an estimated 38.6 million people worldwide were living with HIV infection or AIDS at the end of 2005. ${ }^{1}$ Sub-Saharan Africa continues to represent the global epicentre of this pandemic, placing an enormous burden on financial and health resources in countries most severely affected by the disease. ${ }^{1}$

Skin disease is often the first presenting feature of HIV infection or AIDS. More than $90 \%$ of patients with HIV/AIDS will develop one or more skin diseases during the course of their illness. ${ }^{2}$ Skin lesions tend to arise in tandem with and may be modified by the stage of the disease (ie a declining CD4 count). Fortunately, the skin is an easily accessible organ to biopsy. In those parts of the world where highly active antiretroviral therapy (HAART) is not freely available, a skin biopsy may provide the first opportunity to diagnose an unsuspected and potentially life-threatening opportunistic infection.

\section{CLINICOPATHOLOGICAL SPECTRUM}

Practicing general anatomical pathologists and dermatopathologists, especially those working in regions where HIV/AIDS is highly prevalent, must be familiar with the spectrum of cutaneous manifestations of HIV/AIDS. Careful clinicopathological correlation is of paramount importance. Although this review focuses mainly on an approach to the histopathological evaluation of skin biopsy material from patients who are known to be infected with HIV, the histopathologist should always maintain a high index of suspicion for undiagnosed HIV/AIDS when the clinical history indicates that a common dermatosis has displayed unusual/atypical clinical features, pursued an abnormal clinical course, exhibited greater clinical severity than anticipated, or failed to respond satisfactorily to standard therapy. ${ }^{2}$

The spectrum of HIV-associated skin disease encompasses a broad range of non-infective dermatoses, infective conditions, adverse drug reactions, and neoplastic proliferations. ${ }^{3-5}$ The non-infective dermatoses may be classified as follows:

- Dermatoses peculiar to HIV infection (eg HIV exanthem, papular pruritic eruption (PPE) of HIV infection).

- Common dermatoses occurring with greater frequency or modified by HIV/AIDS (eg seborrhoeic dermatitis, psoriasis).

- Less common conditions that have been reported in association with AIDS (eg pityriasis rubra pilaris (PRP), Reiter disease). ${ }^{2}$

HIV-related mucosal, nail and hair disorders will not be discussed in this review. ${ }^{3467}$

The pathologist's basic understanding of the clinical differential diagnosis of the range of skin lesions associated with HIV/AIDS is essential to accurate clinicopathological correlation, especially when a certain disease has not been suspected on clinical grounds. In the setting of HIV infection, diverse diseases may present with remarkably similar clinical features, eg giant molluscum contagiosum, cryptococcosis and bacillary angiomatosis (BA), where there are multiple cutaneous nodules, sometimes with umbilication (fig 1). An erroneous clinical diagnosis and failure to perform a confirmatory skin biopsy will inevitably result in delayed treatment or the institution of inappropriate therapy, with potentially fatal consequences (eg cryptococcosis). Certain conditions may also manifest diverse clinical features in the setting of AIDS. Histoplasmosis, for example, may present with erythematous macules, molluscum contagiosum-like papules or nodules, pustules, furuncles, acneiform lesions, abscesses, cellulitis, a rosacealike eruption, an eczematous eruption, a guttate psoriasis-like eruption, ulcers, vegetative plaques, panniculitis, subcutaneous nodules, or even purpuric lesions resembling vasculitis, either alone or in combination. ${ }^{3}{ }^{\text {8-11 }}$ 


\section{ADVERSE DRUG REACTIONS}

Pharmacologically induced cutaneous eruptions are a particularly important aspect of HIV/AIDS. ${ }^{35}{ }^{12-18}$ Such adverse reactions are hardly surprising in the light of the immune dysfunction and the fact that multiple drugs are often prescribed simultaneously. The risk for adverse cutaneous reactions to certain drugs is greatly increased compared with that of the general population (as much as 100 times), and occurs in tandem with the level of immunosuppression. ${ }^{32}$ Exanthematous (morbilliform) eruptions may account for more than $90 \%$ of cases. ${ }^{3}{ }^{17}$ The drugs most often prescribed in HIV-positive (HIV+) patients are antimicrobial agents and antiretroviral agents.

The commonly prescribed combination of trimethoprim and sulphamethoxazole (for prophylaxis against Pneumocystis jiroveci pneumonia), other sulphonamides and the penicillins were responsible for $75 \%$ of adverse cutaneous drug reactions in one series of patients with HIV disease. ${ }^{37}$ Reactions attributable to trimethoprim-sulphamethoxazole occur 10 times more commonly than in the HIV-negative population, manifesting as an exanthematous (morbilliform) eruption in $50-60 \%$ of cases where this drug combination is administered intravenously. ${ }^{3}{ }_{17}$ Reactions to the antituberculous agent isoniazid may be encountered. Antimicrobial agents can also result in erythema multiforme (EM), Stevens-Johnson syndrome (SJS), toxic epidermal necrolysis (TEN), a lichenoid drug eruption or a fixed drug eruption (FDE).

The antiretroviral agents comprise:

- Nucleoside reverse transcriptase inhibitors (NRTIs) such as zidovudine, didanosine, lamivudine, stavudine and zalcibatine.

- Non-nucleoside reverse transcriptase inhibitors (NNRTIs) such as nevirapine and efavirenz.

- Protease inhibitors (PIs) such as ritonavir, amprenavir, indinavir, nelfinavir and saquinavir. ${ }^{319}$

Adverse cutaneous reactions reported with the use of specific NRTIs (especially zidovudine) include mucocutaneous pigmentation, drug hypersensitivity (DRESS; drug rash, eosinophilia, and systemic symptoms), hypertrichosis, leucocytoclastic vasculitis and SJS. ${ }^{13} 19$ Many patients receiving NNRTIs such as nevirapine will develop a skin rash, most often an exanthematous eruption. Other less frequently reported reactions which may manifest in the skin include SJS and potentially life-threatening conditions such as TEN and DRESS. ${ }^{16} 1819$ Lipodystrophy syndrome is the most frequent complication of the PIs. ${ }^{313} 19$ Skin biopsies from such cases are seldom encountered. Other reported reactions to PIs include a maculopapular eruption, urticaria, acute generalised exanthematous pustulosis, asteatotic dermatitis; acute porphyria, DRESS, SJS and single or multiple pyogenic granulomas (PGs) may also occur. ${ }^{3}{ }^{13} 14$ 19-22

The introduction of HAART has in recent years resulted in the emergence of the immune reconstitution inflammatory syndrome (IRIS). This syndrome is characterised by a paradoxical clinical deterioration in or exacerbation of certain conditions, some of which may potentially manifest in the skin. These include mycobacterial infections, human herpes virus infection such as herpes zoster, or an underlying autoimmune disease such as lupus erythematosus. ${ }^{23}$

The possibility of an adverse drug reaction should always be considered in the differential diagnosis of any inflammatory dermatosis in an HIV+ patient. Drugs may give rise to a wide range of histological reaction patterns, including lichenoid, spongiotic, vasculopathic, pustular, vesiculobullous and urticarial reactions. Figures 2-5 illustrate the histological features of some of these adverse drug reactions. It is wise to maintain a high index of suspicion and to always seek a detailed
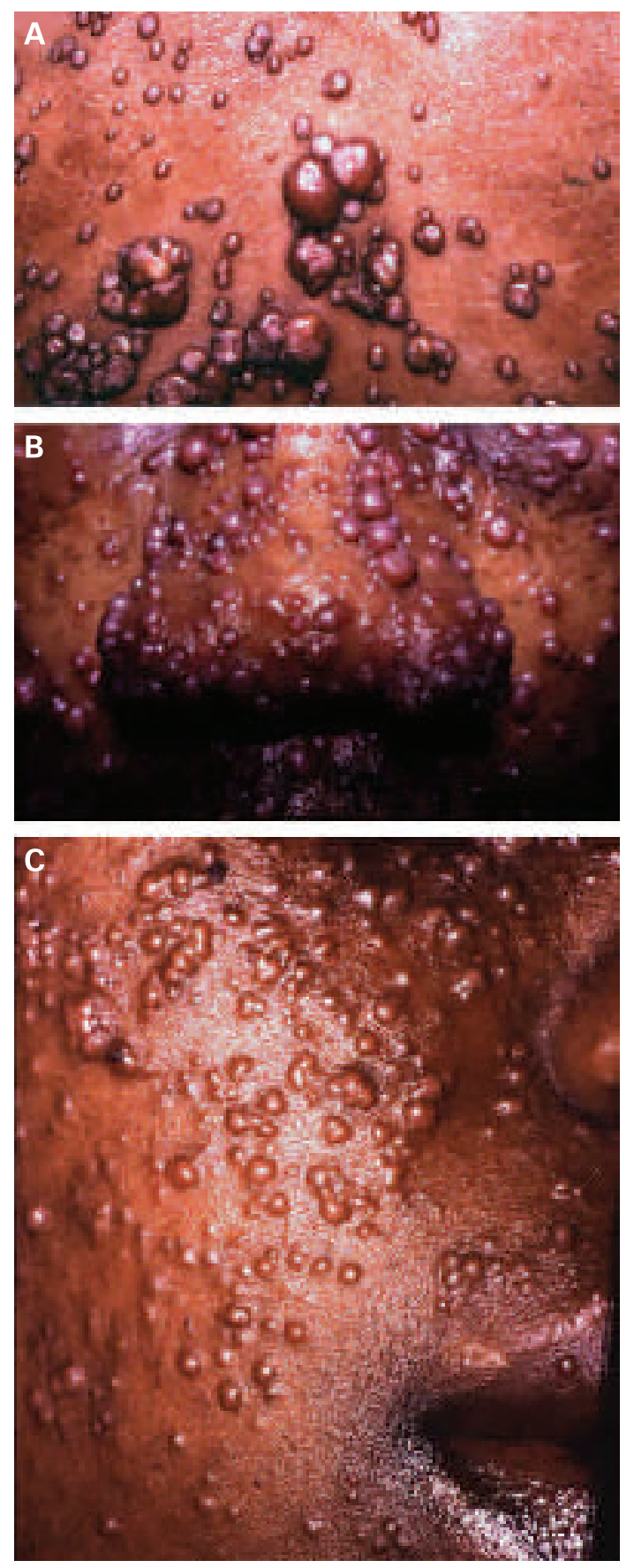

Figure 1 Multiple nodular facial cutaneous lesions in three patients with AIDS: (A) molluscum contagiosum; (B) bacillary angiomatosis; (C) cryptococcosis. Note the considerable clinical overlap between these three conditions.

drug history from the referring clinician when confronted with any of the aforementioned histological patterns. Although the presence of eosinophilic leucocytes and/or plasma cells amid the dermal inflammatory infiltrate may provide an important clue to a drug-related eruption, their absence does not necessarily militate against a pharmacologically induced process.

\section{DIAGNOSTIC APPROACH}

\section{General principles}

A useful approach to the HIV+ skin biopsy is to apply the same broad principles employed in all dermatopathology cases, 


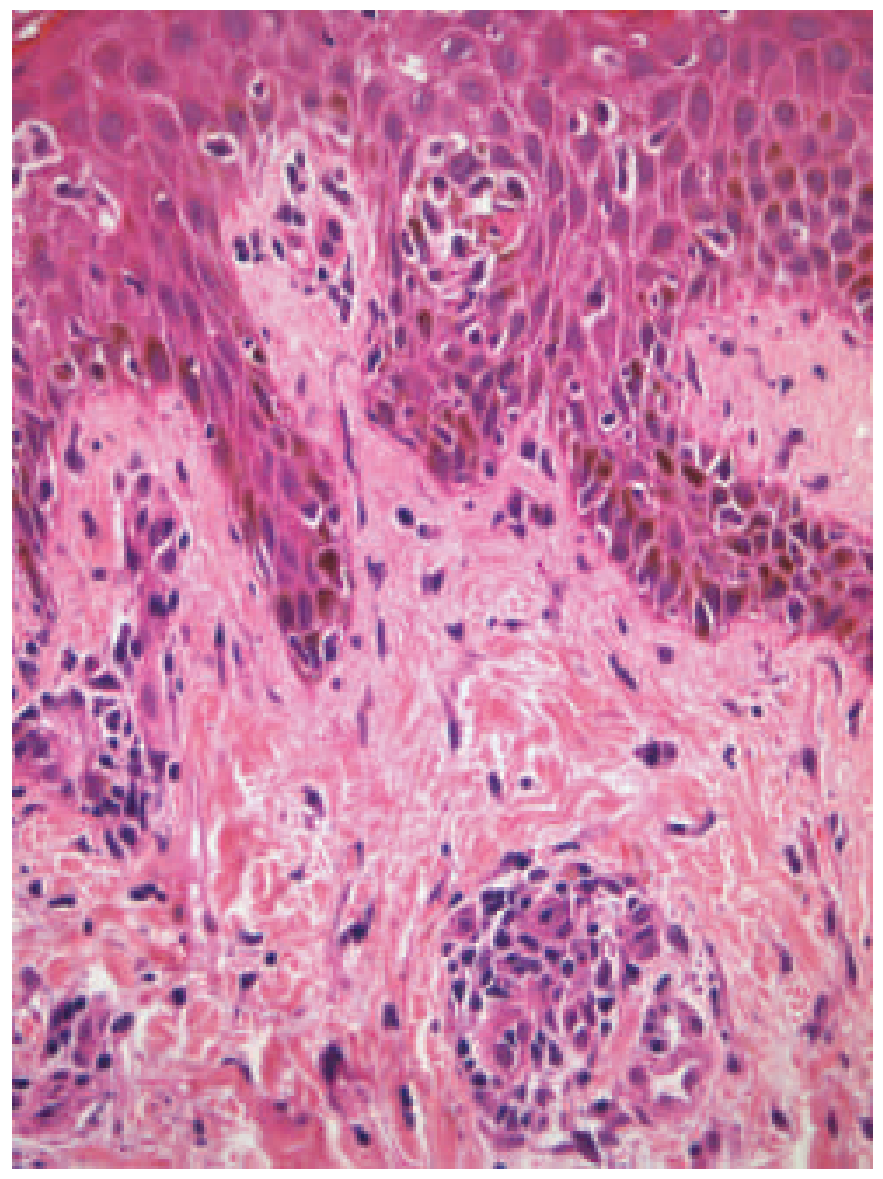

Figure 2 Morbilliform drug eruption in a patient receiving highly active antiretroviral therapy (HAART). Note the mild lichenoid and spongiotic reactions, and subtle lymphocytic vasculopathic reaction in the upper dermis.

namely categorisation of the major histological reaction pattern, with subsequent interpretation in the context of the presenting symptoms/signs and an appropriate clinical differential diagnosis. Unless a diagnosis is obvious in the initial H\&E-stained section(s), careful examination of multiple serial sections should always be undertaken. On arriving at a presumptive histopathological diagnosis or differential diagnosis, it may be appropriate to request additional histochemical, immunohistochemical or molecular investigations to facilitate a more definitive diagnosis. It may also be necessary to recommend that one or more additional skin biopsies be performed for specific microbiological investigations when an infective process is suspected. Multiple biopsies should also be recommended if there is any clinical suspicion of multiple disease processes. Rarely, these may manifest in a single biopsy specimen. It is, therefore, essential that skin biopsies from patients infected with HIV are always carefully examined for the presence of dual (or multiple) pathological processes (fig 6).

\section{Psoriasiform reaction pattern}

This reaction pattern is a typical feature of seborrhoeic dermatitis (SD), the most common cutaneous manifestation of HIV disease. Other conditions that may manifest with a psoriasiform pattern on biopsy include psoriasis, Reiter disease, pityriasis rubra pilaris (PRP), secondary syphilis and the AIDSassociated acrodermatitis enteropathica-like eruption.

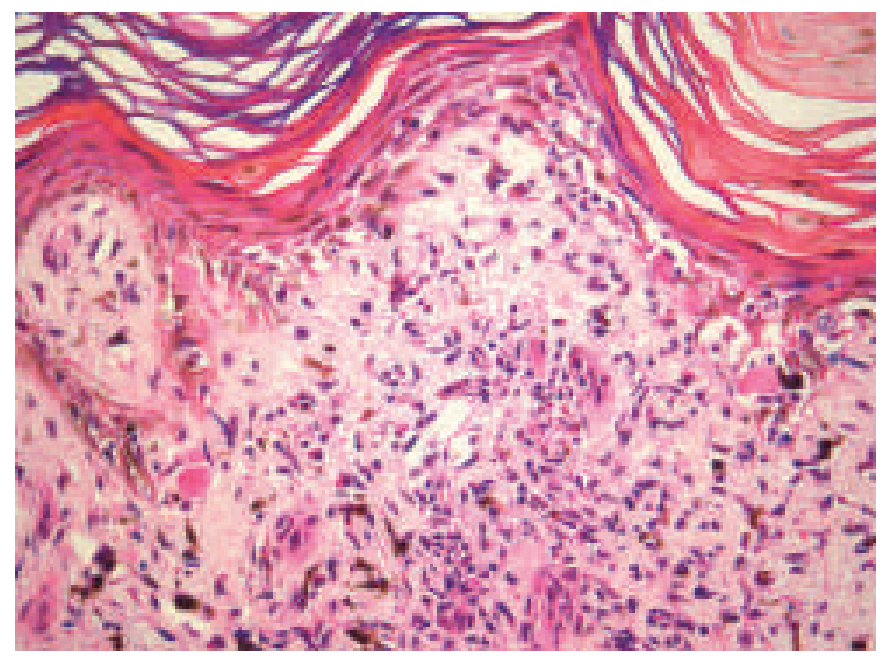

Figure 3 Lichenoid drug eruption in an HIV-infected patient who recently commenced antituberculous therapy.

In excess of $80 \%$ of patients may develop SD during the course of their illness, and it is sometimes the presenting feature of undiagnosed retroviral infection. ${ }^{4524-26}$ In addition to the usual features of $\mathrm{SD}$, such as mild spongiosis, hyperkeratosis and focal parakeratosis (fig 7A), HIV/AIDS-associated cases sometimes exhibit additional features, including more extensive parakeratosis, more marked lymphocytic exocytosis, occasional apoptotic keratinocytes (fig 7B), and/or a contingent of plasma cells and neutrophils amid the upper dermal lymphoid infiltrate, with or without small amounts of karyorrhectic debris. ${ }^{42-27} \mathrm{~A}$ periodic acid-Schiff (PAS) stain should be performed to rule out a concomitant dermatophyte infection. ${ }^{4}$

Although the incidence of psoriasis does not appear to be increased in HIV/AIDS, patients can present with atypical and severe forms of the disease. ${ }^{4}{ }^{27}$ Histological features are similar to non-HIV-associated cases, with the possible addition of plasma cells in the dermal infiltrate. ${ }^{424} 27$ Munro microabscess formation is less frequent, more irregular acanthosis may be encountered and there is less conspicuous thinning of the suprapillary epidermis. ${ }^{28}$ The pustular variant may be histologically indistinguishable from Reiter disease; careful clinicopathological correlation is, therefore, essential. PRP has been reported in association with HIV infection. ${ }^{29}{ }^{30}$ Multiple serial sections are often required to identify the geometric parakeratosis that characterises this disease (fig 8).

A close relationship exists between syphilis and HIV infection. The disease may manifest with atypical clinical features. Furthermore, the time frame for progression from primary to tertiary syphilis can be greatly accelerated in patients with AIDS. ${ }^{41-33}$ Secondary syphilis shows a dense dermal lymphohistiocytic infiltrate rich in plasma cells, with variable interface dermatitis (fig 9A). Although a deep dermal plasma cell infiltrate is typical, this is sometimes relatively inconspicuous in HIV-associated cases. Poorly formed epithelioid granulomas are a feature of late secondary lesions. ${ }^{31}$ Nodulo-ulcerative and rupial lesions are not uncommon in patients with concomitant HIV infection. Biopsies from such lesions show more florid epidermal hyperplasia with spongiosis and neutrophilic infiltration. ${ }^{31} 35$ Sections stained with the Warthin-Starry (WS) method may reveal Treponema pallidum spirochaetes, provided that antimicrobial agents have not already been administered to the patient (fig 9B). The organisms may also be demonstrated by immunohistochemistry. ${ }^{4}$ 


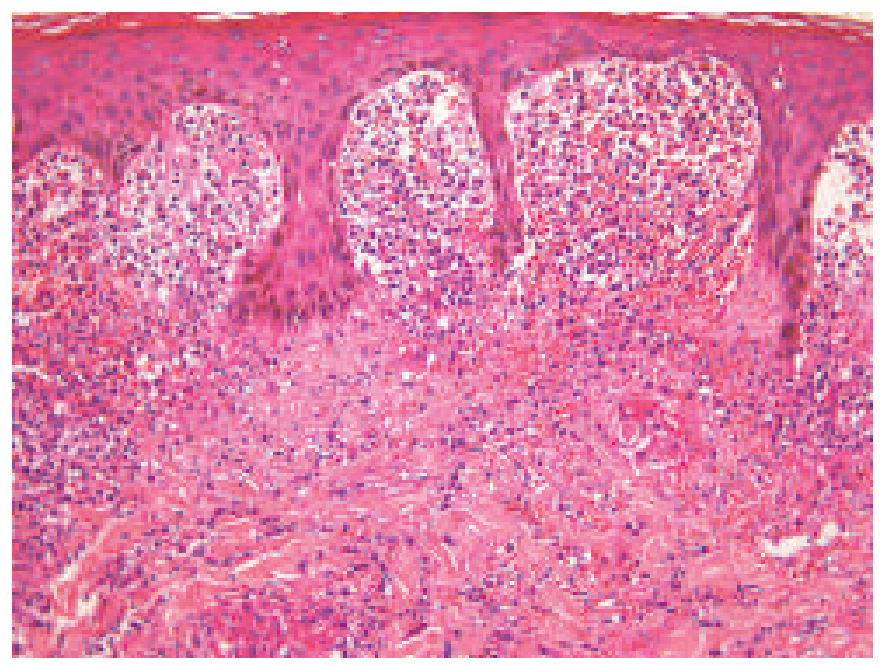

Figure 4 Leucocytoclastic vasculitis ascribed to highly active antiretroviral therapy (HAART), with early subepidermal vesiculation.

The rare acrodermatitis enteropathica-like eruption associated with AIDS is due to a transient symptomatic zinc deficiency. ${ }^{36}$ Careful correlation with the clinical picture is essential before entertaining this diagnosis. The histopathology varies according to the duration of the disorder. Early lesions are characterised by confluent parakeratosis, increasing pallor of epidermal keratinocytes and progressive acanthosis. Massive ballooning degeneration of keratinocytes eventually results in intra-epidermal vesiculation. Confluent epidermal necrosis may ensue. Biopsies from late lesions are characterised by psoriasiform acanthosis and confluent parakeratosis, without significant epidermal pallor. ${ }^{36}$

\section{Lichenoid reaction pattern}

Skin biopsies showing this reaction pattern probably require the greatest level of clinicopathological correlation in $\mathrm{HIV}+$ patients. A detailed drug history and knowledge of the nature and distribution of the lesions are particularly important, as a lichenoid reaction typifies a range of pharmacologically-induced cutaneous eruptions. These may exhibit considerable histological overlap, and include conditions such as EM, SJS, fixed drug eruption and lichenoid drug eruption (figs 3, 5). Drugs implicated include antimicrobial agents (eg trimethoprimsulphamethoxazole, other sulphonamides, penicillins, isoniazid) and certain antiretroviral drugs, including didanosine, nevirapine and the PIs. ${ }^{3} 161819$ EM may also be triggered by other factors, including infection with herpes simplex virus (HSV) or Pseudomonas spp.

A lichenoid reaction ("interface dermatitis") may also be encountered in secondary syphilis (fig 9A); recognition of the other histological features of this condition and correlation with the clinical picture and appropriate serological investigations, however, should facilitate the diagnosis. ${ }^{31}$ Chronic actinic dermatitis (CAD) in AIDS may exhibit a lichenoid reaction. ${ }^{37}$ Additional findings include spongiosis, vertical streaking of dermal collagen and stellate dermal myofibroblasts. ${ }^{37}$ Although not specific to HIV/AIDS associated cases, the dermal inflammatory infiltrate often contains eosinophils and plasma cells; an adverse drug reaction may therefore enter the differential diagnosis.. Lymphocyte-mediated destruction of basal melanocytes may account for the vitiligo-like depigmentation observed in some cases (personal observation).

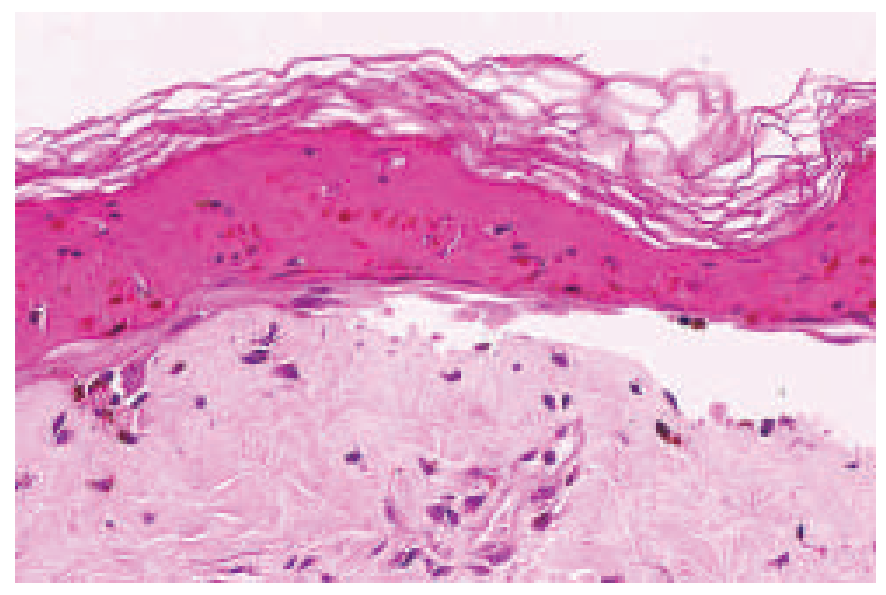

Figure 5 Stevens-Johnson syndrome ascribed to nevirapine. Note the non-viable epidermis and subepidermal bulla formation.

The presence of a lichenoid reaction in addition to mild spongiosis and lymphocytic vasculitis should alert one to either a morbilliform drug eruption or acute HIV exanthem (figs 2, 10); this emphasises the need for careful clinicopathological correlation. $^{35}$

A potentially controversial entity is the so-called "AIDS interface dermatitis". ${ }^{38}$ Patients have invariably had one or more opportunistic infections and have received at least one medication prior to the onset of the cutaneous eruption. The current view, therefore, is that this "condition" probably does not represent a discrete clinicopathological entity. It has, however, been the author's experience that interface dermatitis may occasionally be detected incidentally in a biopsy performed for another reason (eg confirmation of Kaposi sarcoma (KS)); such cases often do not have a significant drug history.

\section{Spongiotic reaction pattern}

A spongiotic reaction with lymphocytic exocytosis may be seen in SD. Mild lymphocytic exocytosis can also be encountered in AIDS-associated CAD, the acute exanthem of HIV infection and morbilliform (exanthematous) drug eruptions (figs 2,10$).^{3} 537$

The differential diagnosis of a spongiotic reaction with prominent neutrophilic exocytosis (ie spongiform pustule formation) in the context of HIV/AIDS includes pustular psoriasis, Reiter disease and acute generalised exanthematous pustulosis. $^{39-42}$ A superficial fungal infection should also be considered.

\section{Intradermal pustular reactions}

When a skin biopsy shows intradermal neutrophilic pustule formation, it is useful to examine serial sections to determine if the pustule has evolved as a consequence of intradermal rupture of a folliculocentric process, or if pustule formation is associated with evidence of a vasculitic process. Vasculitides associated with intradermal suppuration are discussed in more detail in the section on vasculitis below.

A picture of acute suppurative folliculitis is frequently attributable to a bacterial infection (usually Staphylococcus spp.), including clinical variants such as furunculosis. ${ }^{43} 44$ Pityrosporum folliculitis (due to Malassezia globosa) with intradermal rupture may produce a similar picture. ${ }^{43} 45$ Appropriate histochemical stains should be performed for confirmation of the diagnosis (eg Gram, PAS). Acne conglobata 

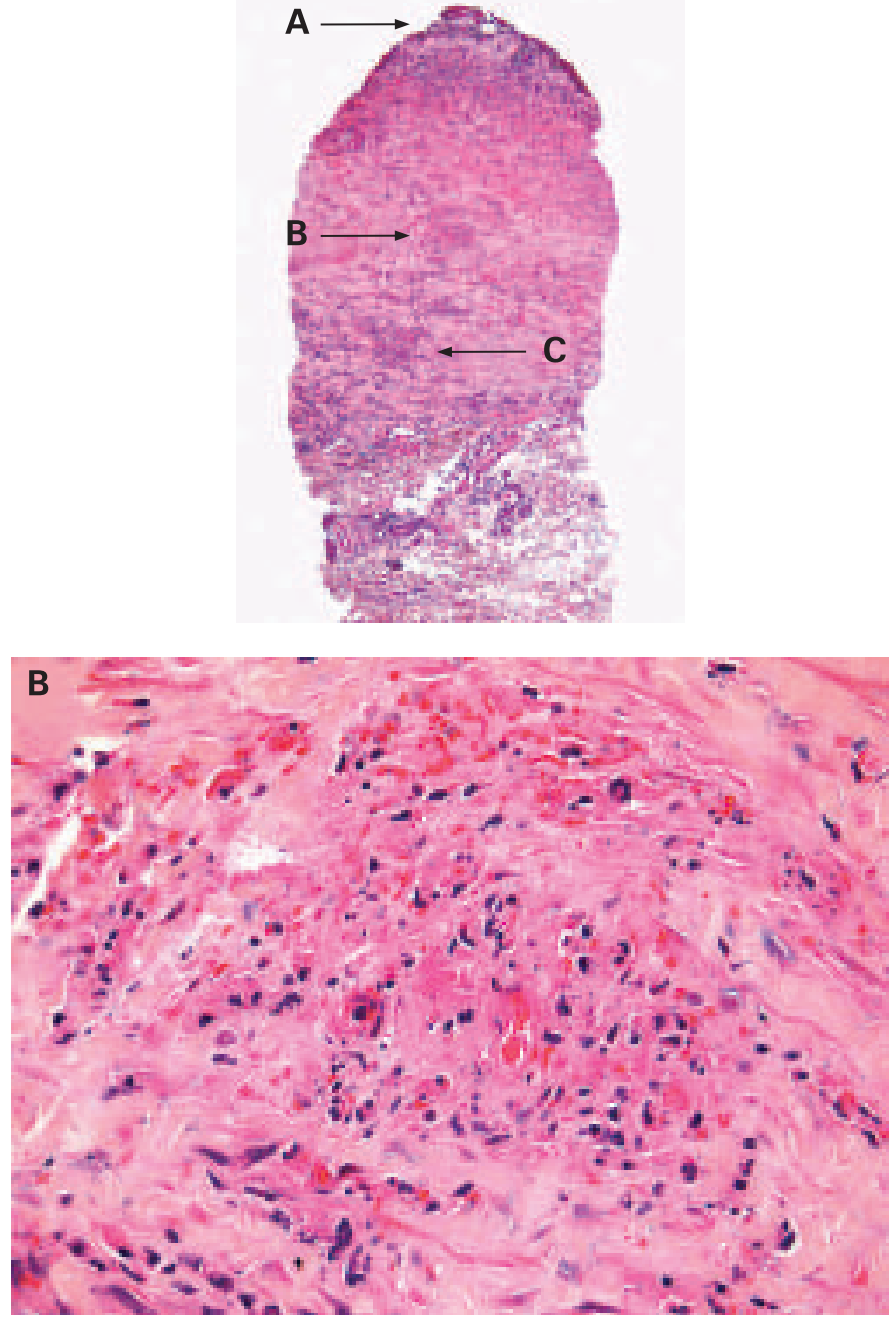
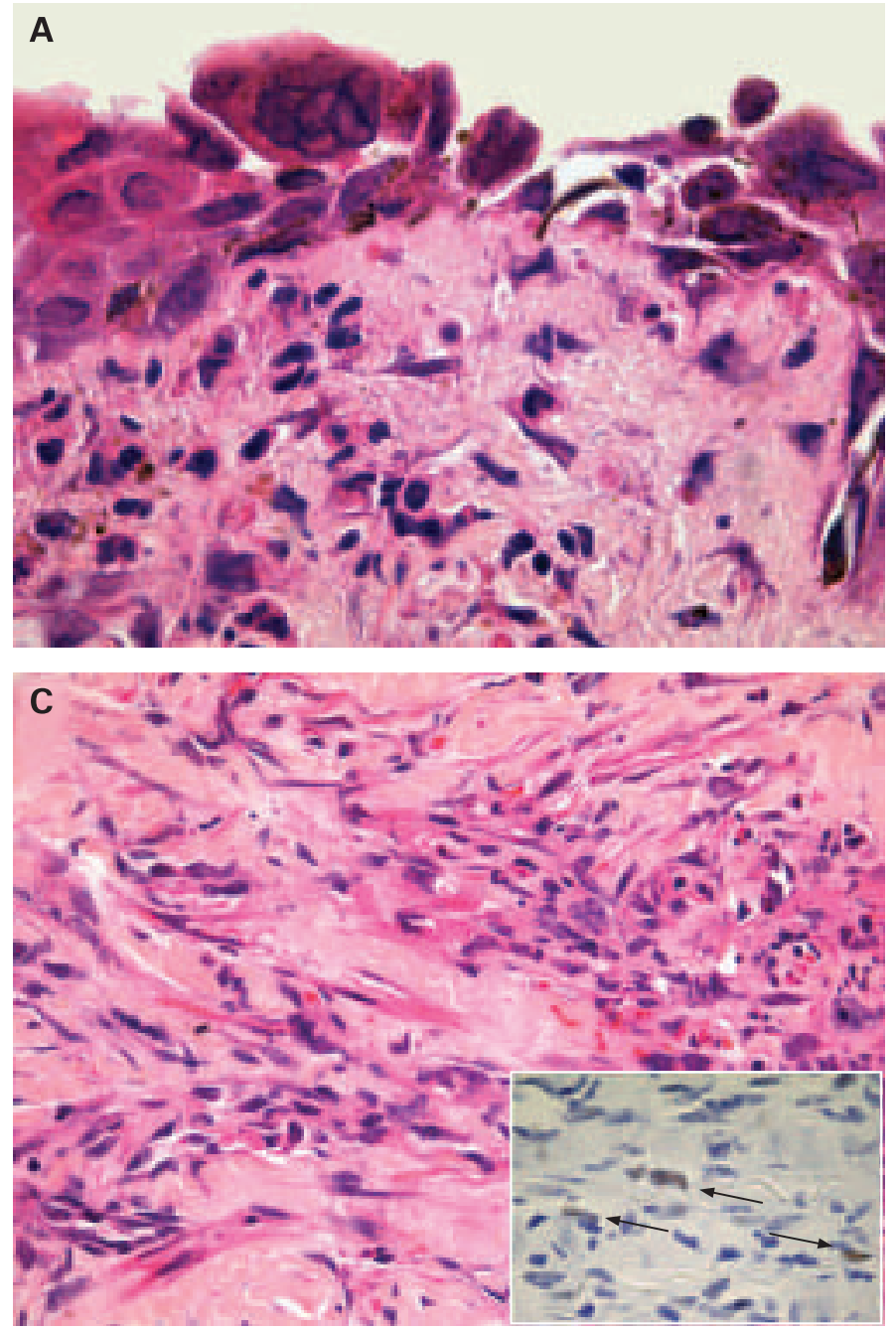

Figure 6 Skin biopsy showing multiple pathological processes, including superficial vesiculation due to varicella zoster virus infection (A), leucocytoclastic vasculitis in the mid to upper dermis (B), and incidental Kaposi sarcoma in the deep dermis (C). The latter was confirmed by immunohistochemical staining for HHV-8 (inset).

and hidradenitis suppurativa form part of a spectrum of conditions associated with follicular occlusion. A skin biopsy often reveals intradermal abscesses associated with disrupted hair follicles, typically with sinus tract formation. ${ }^{46}$ A granulomatous reaction along the periphery of the intradermal abscess can be a useful clue to potential recognition of a ruptured folliculocentric suppurative process in deeper tissue sections (fig 11).

In patients with AIDS, intradermal abscess formation is invariably indicative of an infective process, and often attributable to an opportunistic pathogen. Special stains for infective organisms are mandatory in all biopsies manifesting this reaction pattern. A basic panel should always include PAS, Grocott and Ziehl-Neelsen (ZN) stains. Additional biopsies should be recommended for bacterial, fungal and mycobacterial culture. Although most deep (invasive) fungal infections are typified by suppurative granulomas, skin biopsies from immunocompromised individuals with such infections may reveal only dermal abscess formation without an associated granulomatous response, eg cryptococcosis or coccidiodomycosis. ${ }^{47-50}$ The early phase of blastomycosis is usually characterised by a neutrophilic rather than a granulomatous response. ${ }^{51}$ Disseminated sporotrichosis may occur in the setting of AIDS and skin biopsies sometimes reveal rare Sporothrix schenkii spores that are devoid of the characteristic Splendore-Hoeppli phenomenon with asteroid body formation. ${ }^{52}$

Disseminated cutaneous tuberculosis (miliary tuberculosis of the skin) may similarly present with superficial intradermal abscesses in the absence of associated granulomatous inflammation (fig 12). ${ }^{53}$ The early phase of certain non-tuberculous mycobacterial infections such as Mycobacterium marinum, $M$ fortuitum chelonae or $M$ kansasii infection is characterised by neutrophilic abscess formation rather than a granulomatous tissue reaction. ${ }^{54-56}$ Botryomycosis, a condition which does not have a strong association with AIDS, shows intradermal abscesses containing colonies of blue-staining bacteria (usually Staphylococcus aureus) surrounded by a conspicuous SplendoreHoeppli phenomenon. ${ }^{57}{ }^{58}$ A Gram stain or Brown-Hopps (BH) stain confirms the diagnosis.

\section{Vasculopathic reaction}

Careful clinicopathological correlation is particularly important in skin biopsies showing a vasculitic reaction. A useful approach is to determine which of five potential patterns is evident: 

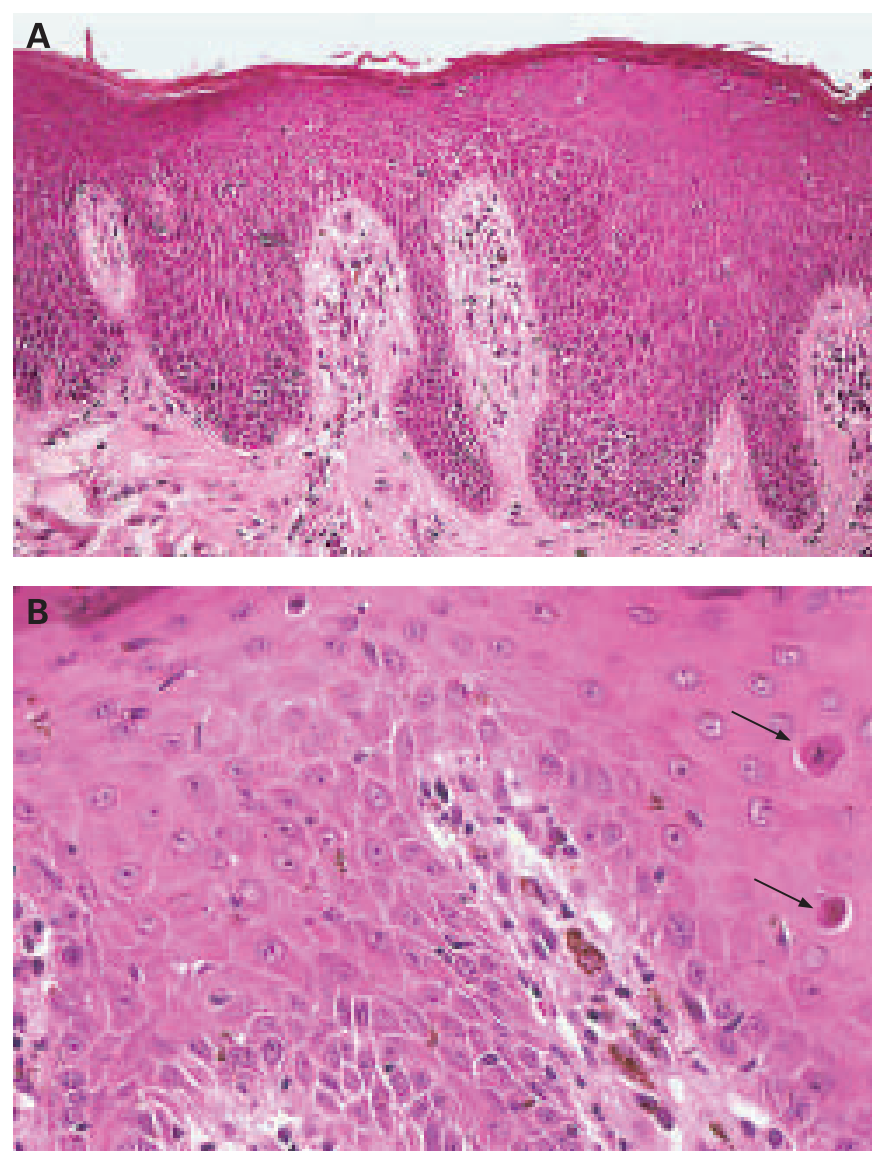

Figure 7 (A) HIV-associated psoriasiform seborrhoeic dermatitis.

(B) Apoptotic keratinocytes (arrows) are frequently encountered in such cases.

- Lymphocytic vasculitis (LyV).

- Leucocytoclastic vasculitis (LCV) of small dermal vessels.

- Neutrophilic vasculitis with vascular thrombosis and intradermal suppuration.

- Vasculitis with palisaded neutrophilic and granulomatous dermatitis.

- Large vessel vasculitis affecting subcutaneous vessels.

The last three patterns usually infer systemic involvement.

The depth of the biopsy is important. Although a shave biopsy or superficial punch biopsy may be sufficient for recognition of LyV or LCV, a deep punch biopsy or even an incisional biopsy (inclusive of subcutaneous tissue) is required for recognition of the other vasculitides. ${ }^{59}$

LyV has many potential causes, but in the context of a biopsy from an HIV-infected patient, a differential diagnosis of acute exanthem of HIV infection or a morbilliform drug eruption should be considered, especially if there is concomitant spongiosis or basal vacuolar degeneration (figs 2,10$).^{35}$

A neutrophilic (leucocytoclastic) vasculopathic reaction in the HIV+ individual may have many potential causes, including infection with HIV per se. ${ }^{60}$ Other viral causes of hypersensitivity vasculitis include cytomegalovirus (CMV), hepatitis B virus, and Epstein-Barr virus. ${ }^{60}{ }^{61}$ The dermal vessels in skin biopsies from cases of HSV or varicella zoster virus (VZV) infection frequently exhibit LCV (fig 6B). ${ }^{462} 63$ Recurrent varicella may even manifest with vasculitis in the absence of epidermal involvement. ${ }^{63}$ Drugs that may precipitate LCV include certain HAART agents, penicillin and the

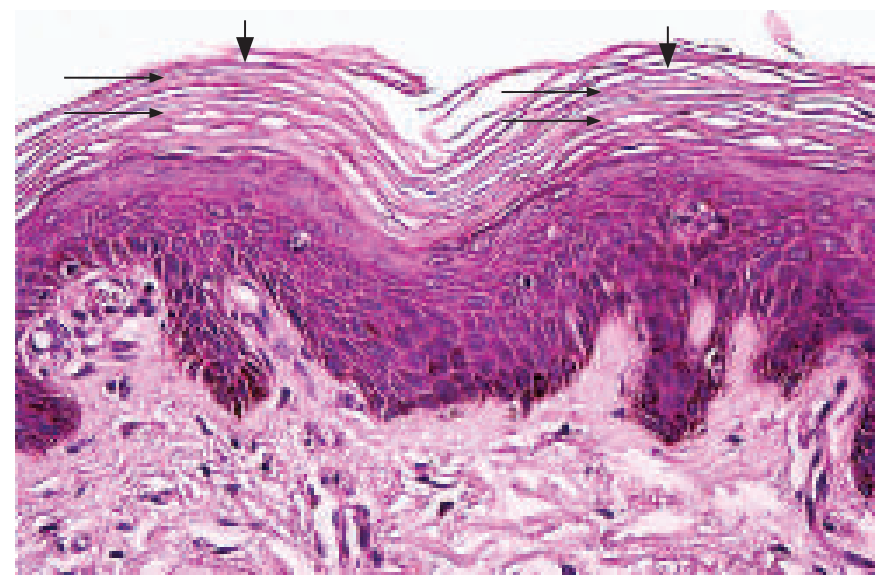

Figure 8 Pityriasis rubra pilaris. Multiple serial sections may be required to show the characteristic geometric parakeratosis, with alternating hyperkeratosis and parakeratosis in horizontal and vertical planes (long and short arrows, respectively).

sulphonamides (fig 4). ${ }^{39}$ Henoch-Schönlein purpura has been reported in association with HIV infection. ${ }^{60} 64$ Erythema elevatum diutinum (EED) has a characteristic clinical picture, and skin biopsies from such cases will reveal LCV associated with neutrophilic dermatosis and an admixed population of eosinophilic leucocytes. ${ }^{60}{ }^{65} \mathrm{EED}$ may also mimic KS sarcoma clinically. ${ }^{66}$ The author has encountered a case of AIDS-related cutaneous strongyloidiasis manifesting with intradermal larvae and concomitant vasculitis (fig 13).

The presence of acute LCV in association with vascular occlusion may signify either HIV-associated mixed cryoglobulinaemia (with small vessel occlusion by cryoglobulin precipitates) or septic vasculitis (with dermal vascular occlusion by infected microthrombi). ${ }^{67}{ }^{68}$ The latter may be associated with intradermal abscess formation and/or cutaneous infarction (fig 14). Special stains (eg Gram, BH) may confirm the presence of infective microorganisms within rare occlusive thrombi, although these bacteria are often elusive, even when multiple serial sections are examined. In papulonecrotic tuberculide (PNT), serial sections will reveal vasculitis at the apex of a wedge-shaped zone of cutaneous infarction. ${ }^{69}$ Similar findings may also be encountered in malignant atrophic papulosis (Degos disease), a condition only rarely reported in association with AIDS. ${ }^{70}$ Cutaneous Acanthamoeba infection may also be associated with LCV. ${ }^{71}$ Histoplasmosis is capable of mimicking LCV at a clinical and a histological level. ${ }^{478}$

The presence of vasculitis in association with palisaded neutrophilic and granulomatous dermatitis in a skin biopsy invariably implies systemic disease. Causes in HIV infected patients include Churg-Strauss syndrome (CSS), Takayasu arteritis, polyarteritis nodosa (PAN) and certain infections, including HIV. ${ }^{72}{ }^{73}$ Shave biopsies or superficial punch biopsies from cases of CSS or PAN may reveal only small vessel LCV involving vessels in the upper dermis. ${ }^{59}$ It is therefore essential that biopsies from such cases are of sufficient depth. ${ }^{59}$ Deep punch biopsies or incisional biopsies (that include subcutaneous tissue) are required for the diagnosis of vasculitis affecting deep muscular vessels at the dermal-subcutaneous interface or within the subcutis, such as PAN or nodular vasculitis (erythema induratum (EI) of Bazin), the latter representing a tuberculid in the presence of underlying tuberculosis (fig 15)..$^{59} 6774$ 

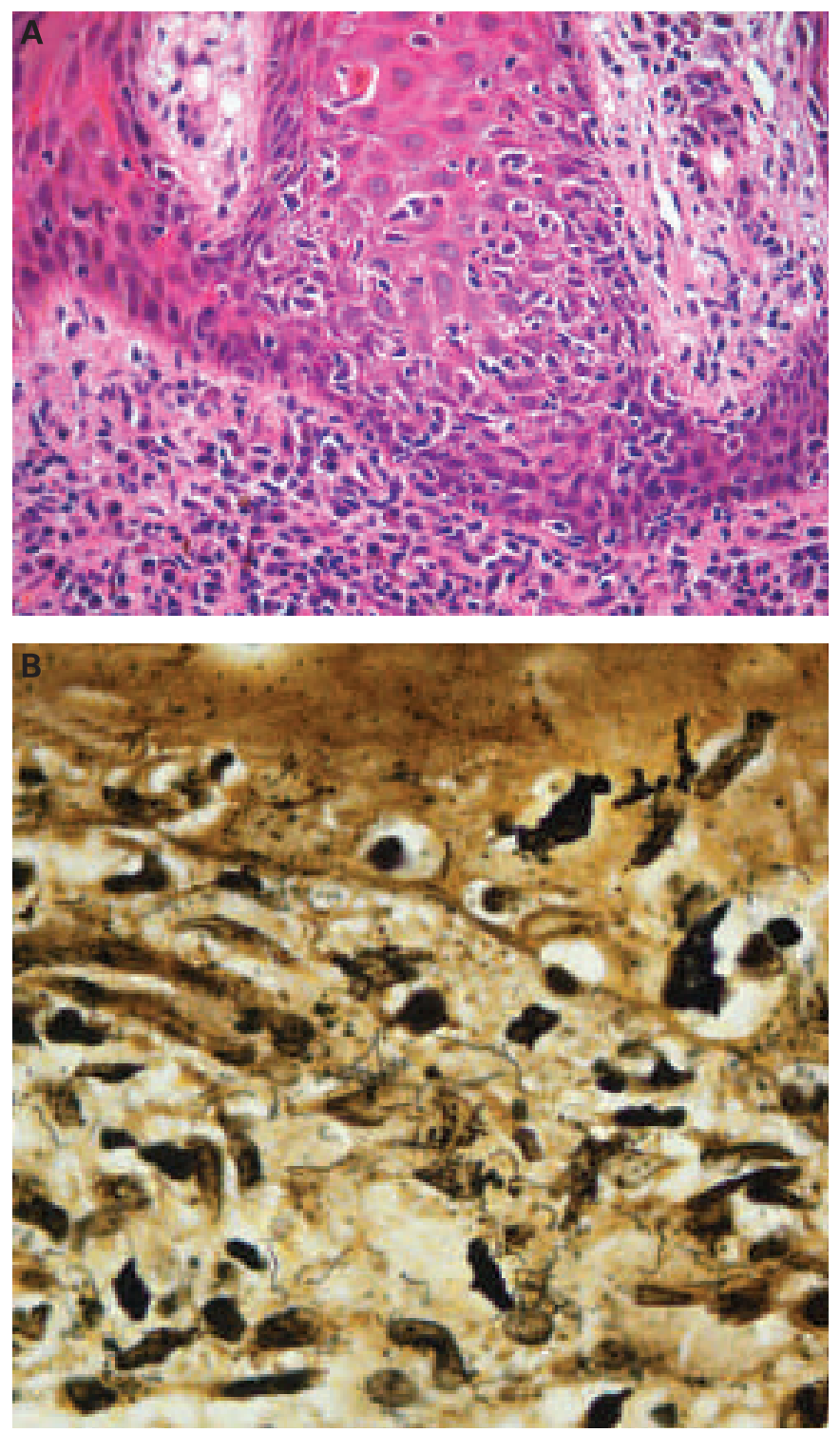

Figure 9 (A) Lichenoid reaction in secondary syphilis, with plasma cell rich dermal inflammatory infiltrate. (B) Numerous Treponema pallidum spirochaetes are seen in this section stained with the Warthin-Starry method.

\section{Granulomatous reaction}

The presence of a granulomatous reaction is usually indicative of an infective process. It is, however, useful to examine multiple serial sections from the outset since there are circumstances in which granulomatous inflammation in the dermis may be secondary, including a perifollicular granulomatous reaction to suppurative folliculitis with intradermal rupture (fig 11), and cases of granulomatous vasculitis. ${ }^{436067}$ The presence of true suppurative granulomas, especially if associated with overlying pseudoepitheliomatous hyperplasia of the epidermis, should prompt a careful search for fungal organisms, including the use of special stains (PAS, Grocott), serial sections and the recommendation for additional samples for fungal culture. ${ }^{4}$ Mycobacterial infections, especially infections with atypical mycobacteria, may produce a similar picture; special stains for acid-fast bacilli are mandatory and the submission of additional samples for mycobacterial culture should be advised. ${ }^{4}$ It is not uncommon for cases of scofuloderma to

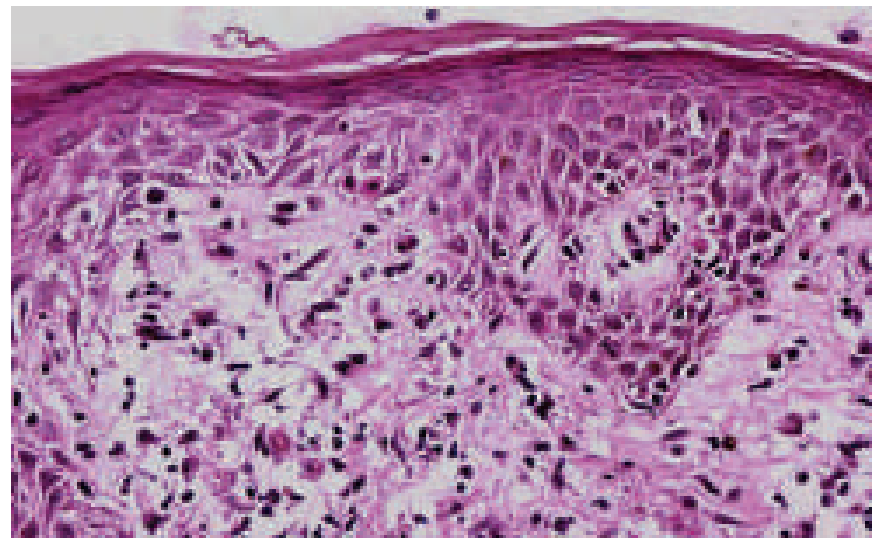

Figure 10 Acute exanthem of HIV infection. Note the mild spongiotic and lichenoid reactions, and the subtle lymphocytic vasculopathic reaction in the superficial dermis.

exhibit cutaneous ulceration and a neutrophilic infiltrate in addition to granulomas. ${ }^{4}$ Granulomatous inflammation with caseous-like necrosis is often observed in association with vasculitis in the panniculus of patients with EI (fig 15).

Cases of cutaneous tuberculosis (eg lupus vulgaris, scrofuloderma) may or may not manifest with caseous necrosis. It is also important to note that reactivation of tuberculosis is a well-recognised manifestation of IRIS in patients receiving HAART ${ }^{23}$ The differential diagnosis of caseating granulomatous

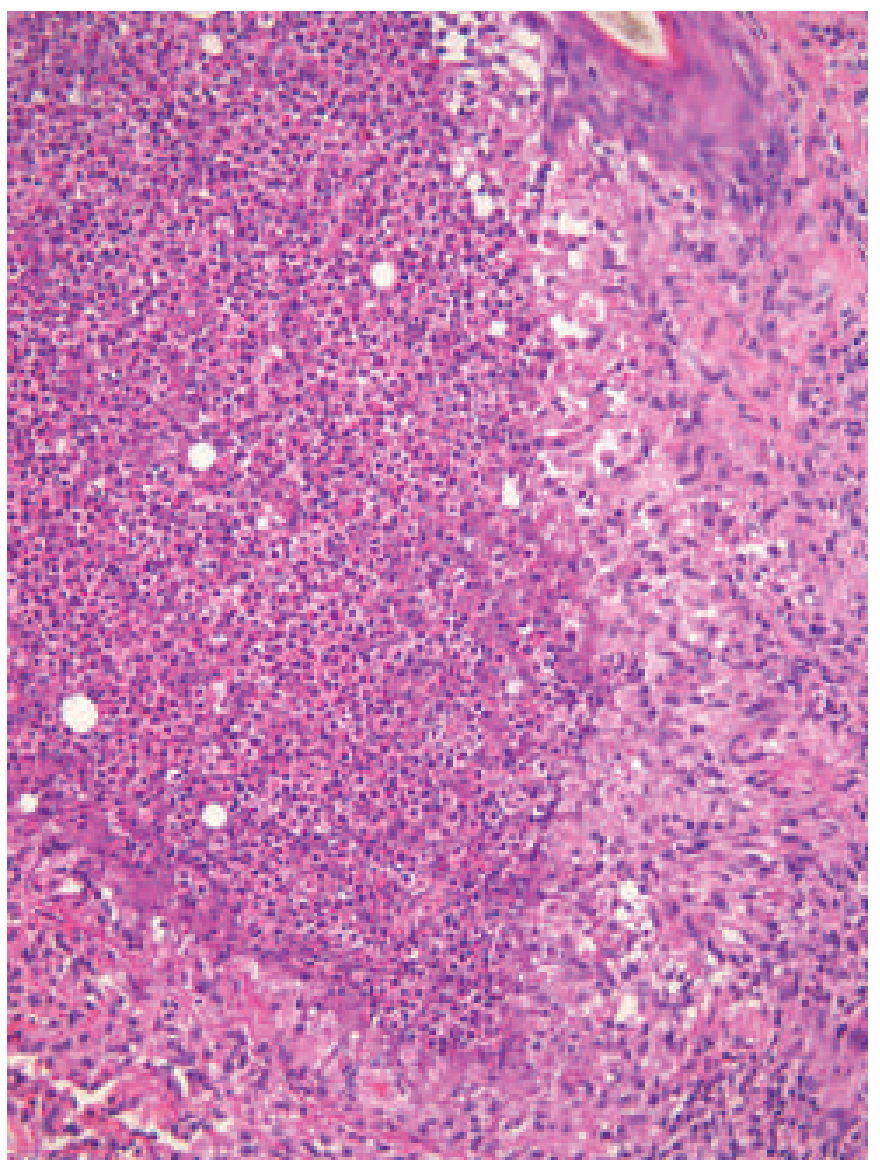

Figure 11 Acute suppurative folliculitis. Intradermal rupture has elicited a perifollicular granulomatous reaction. The remnant of the disrupted follicle at the top of the field is an important diagnostic clue. 

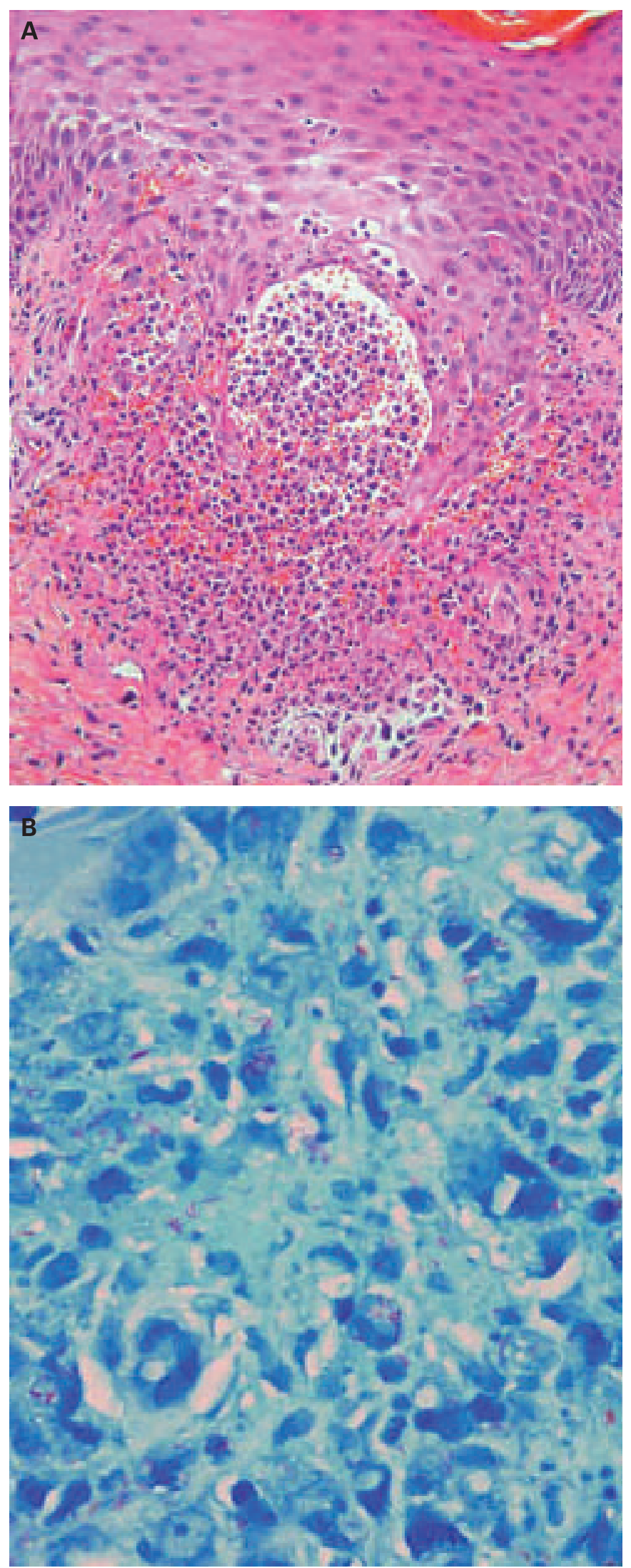

Figure 12 (A) Disseminated cutaneous tuberculosis in a patient with advanced AIDS. Note the subepidermal abscess formation and conspicuous absence of a granulomatous reaction. (B) ZiehlNeelsen staining usually reveals many acid-fast mycobacterial bacilli.

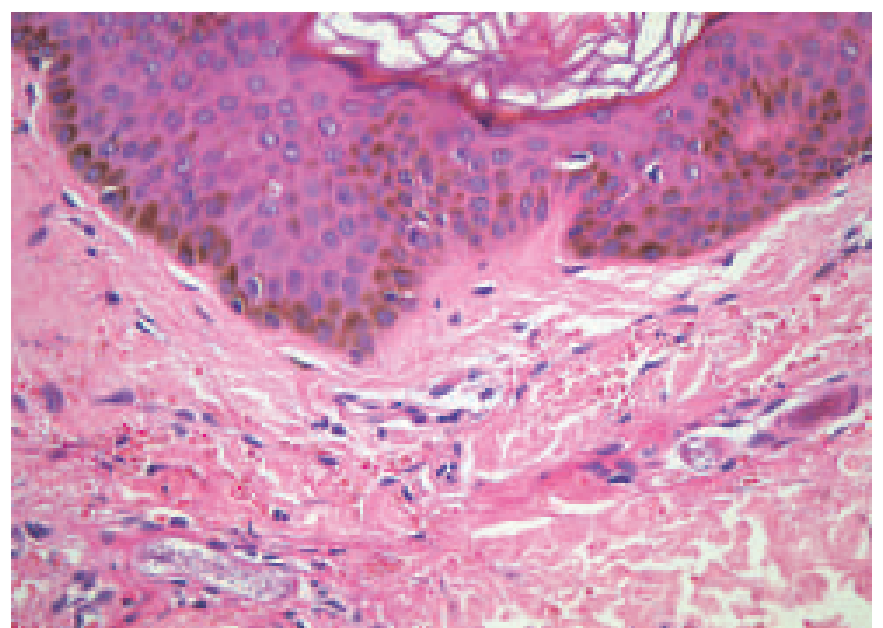

Figure 13 Cutaneous involvement by strongyloidiasis. The presence of Strongyloides larvae in the superficial dermal capillaries has elicited a mild vasculitic reaction.

inflammation includes tertiary syphilis with gummatous nercrosis; careful clinicopathological correlation is, therefore, essential. ${ }^{31}$ The presence of poorly formed dermal granulomas in association with plasmacytosis and a concomitant lichenoid reaction should always alert one to the possibility of (late) secondary syphilis. ${ }^{31}$ Although cutaneous lesions of cryptococcosis (the commonest systemic mycosis in patients with AIDS) may elicit a granulomatous host response, biopsies from

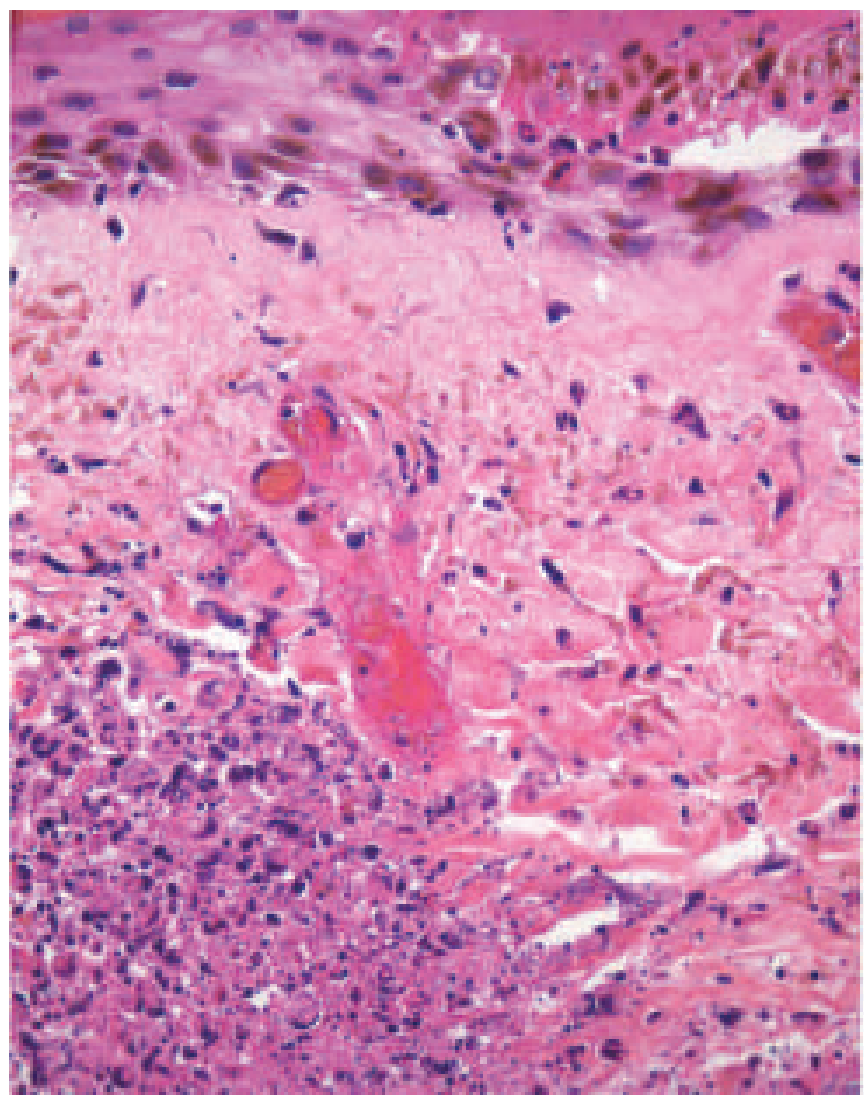

Figure 14 Septic (pustular) vasculitis. with intradermal abscess adjacent to the occluded blood vessel. There is partial infarction of the overlying epidermis. 


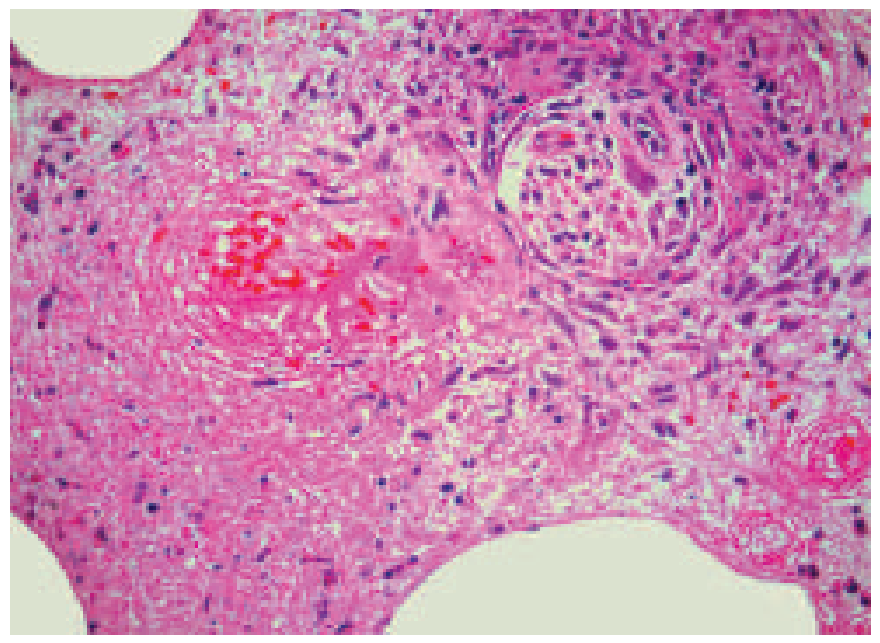

Figure 15 Erythema induratum (nodular vasculitis). There is evidence of vasculitis in the panniculus, accompanied by caseous-like necrosis and poorly developed granulomatous inflammation.

profoundly immunosuppressed individuals frequently reveal little by way of dermal inflammation, a reaction referred to as gelatinous cryptococcosis. ${ }^{4576}$ The mucicarmine stain is useful to demonstrate the characteristic mucoid capsule of Cryptococcus neoformans. ${ }^{4}$ A combined PAS-alcian blue will highlight the fungal wall and its surrounding capsule, respectively. It is, however, important to remember that capsule deficient forms of $C$ neoformans may be encountered in patients with AIDS, emphasising the need for fungal stains and additional biopsies for mycology studies. ${ }^{476}$

The presence of a palisaded granulomatous inflammatory response to dermal necrobiosis in an HIV+ patient is almost certainly indicative of granuloma annulare (GA). GA may even be a presenting sign of HIV infection, and often manifests in its generalised form. ${ }^{78}$ Histological evidence of concomitant transepidermal elimination of necrobiotic collagen is indicative of perforating GA. ${ }^{79}$

\section{Cutaneous ulceration}

The presence of ulcerated skin lesions in an individual infected with HIV can have many potential aetiologies. The primary cause may be centred on either the epidermis or the underlying dermis. HSV infection is a common cause of extensive genital and/or perineal ulceration. ${ }^{4}$ In addition to the characteristic intranuclear HSV inclusions within viable and degenerating epidermal keratinocytes at the ulcer edge (or free-lying within the surface exudate), some cases may show histological involvement of hair follicle epithelium (herpetic folliculitis) or dermal vasculitis. ${ }^{62} 80$ Immunohistochemical staining facilitates distinction between HSV-1 and HSV-2 infection. ${ }^{4}$ Biopsy material from cases of HSV infection should always be carefully examined for evidence of concomitant CMV infection, and although inclusions are usually encountered in vascular endothelial cells and stromal cells, their presence has rarely been documented in epidermal keratinocytes in patients coinfected with HSV. ${ }^{81}$ Cutaneous neuritis and syringosquamous metaplasia directly attributable to CMV infection have also been described. ${ }^{82}$ The diagnosis of CMV infection may be confirmed by immunohistochemistry. ${ }^{4}$

It is not uncommon for infective or neoplastic processes centred on the dermis and/or subcutis to be associated with ulceration of the overlying epidermis. Ulceration may complicate such infective

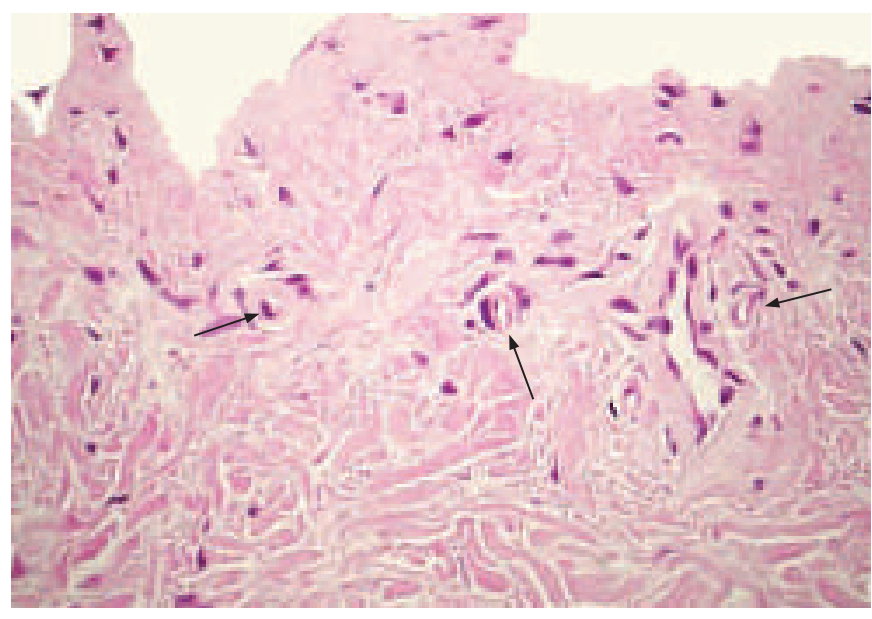

Figure 16 Porphyria cutanea tarda. Subepidermal bulla formation has resulted in loss of the epidermis. Note the rigid papillary dermal capillary walls.

processes as deep fungal infections, tuberculous and nontuberculous mycobacterial infections, certain tuberculides (EI and PNT), lues maligna, leishmaniasis, mucormycosis, cutaneous amoebiasis and acanthamoebiasis. ${ }^{431} 3435546984-86$ AIDS-related neoplasms such as nodular KS and primary or secondary cutaneous B-cell non-Hodgkin lymphoma (NHL) frequently ulcerate. ${ }^{87} 88$ Ulceration may also be attributable to pyoderma gangrenosum or one of the vasculitides. ${ }^{59} 89$

\section{Vesiculobullous reaction}

As with biopsies from non-HIV-infected patients, the first step in the evaluation of a skin biopsy manifesting a vesiculobullous reaction is to ascertain the microanatomical plane of the blister. Intra-epidermal vesiculation may be attributable to viral infections

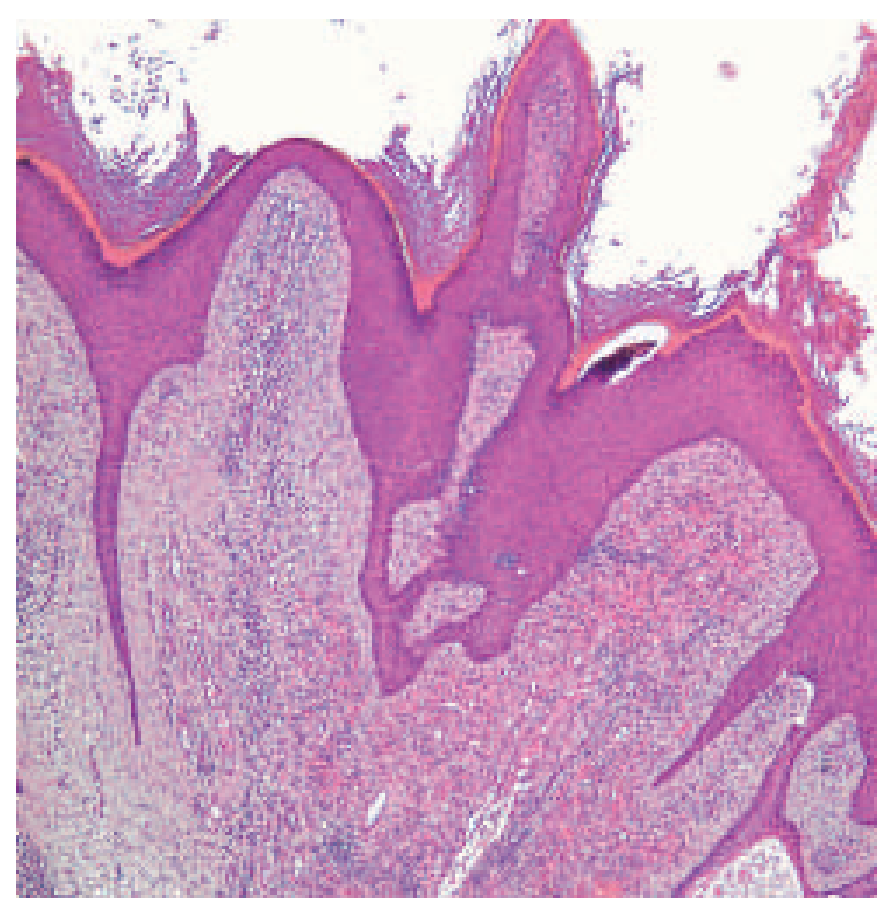

Figure 17 Verrucous Kaposi sarcoma. The acanthotic epidermis overlying the intradermal spindle cell proliferation is papillomatous and hyperkeratotic. 


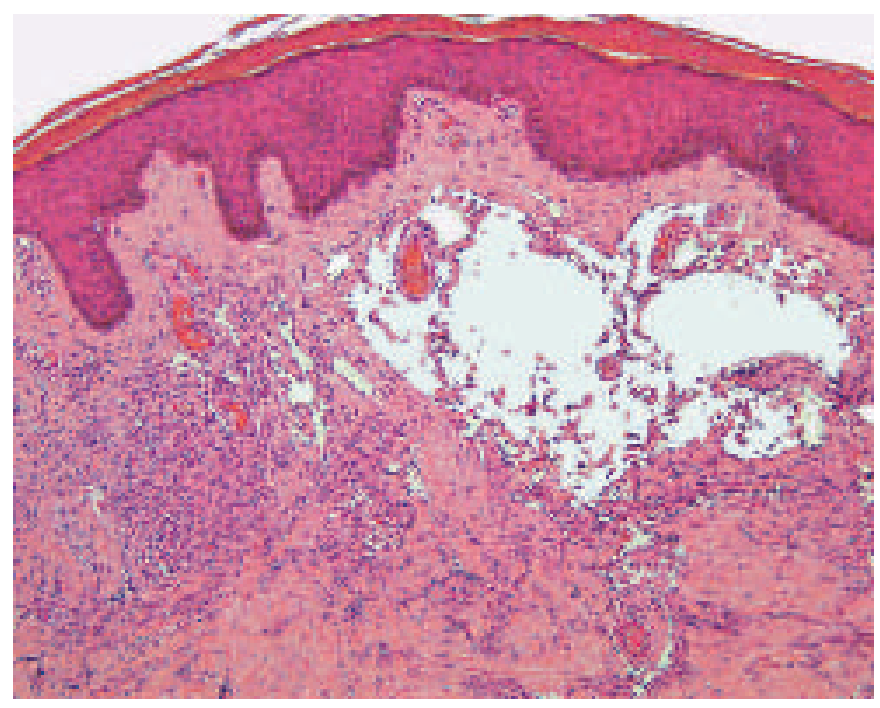

Figure 18 Lymphangioma-like Kaposi sarcoma. Note the ectatic vascular channels flanked by a more typical plaque stage lesion. The promontory sign is well developed.

such as HSV or VZV infection; these usually have identical histological features. Distinction between these infections is, therefore, reliant on the clinical features and appropriate immunohistochemical stains. ${ }^{40}$ The presence of a suprabasilar acantholytic blister in an HIV+ patient may signify Grover disease (transient acantholytic dermatosis) or pemphigus vegetans, although the latter is usually associated with marked epidermal hyperplasia and intra-epidermal eosinophil-rich microabscesses. ${ }^{91} 92$ Intra-epidermal vesiculation due to massive ballooning degeneration of keratinocytes may occur in early lesions associated with the AIDS-related acrodermatitis enteropathica-like eruption. ${ }^{36}$

The presence of a cell-poor subepidermal bulla usually signifies HIV-associated porphyria cutanea tarda and should prompt careful examination of the papillary dermal capillaries for circumferential deposition of hyaline eosinophilic material (fig 16), which stains with PAS.93 TEN shows a cell-poor subepidermal bulla, with minimal dermal inflammation and a non-viable blister roof characterised by confluent keratinocyte apoptosis. The differential diagnosis of a subepidermal blister in association with a lichenoid tissue reaction includes EM and SJS (fig 5); these conditions are discussed earlier in this review. LCV is sometimes associated with subepidermal bulla formation (fig 4).

\section{Vascular proliferations}

The three main categories of HIV/AIDS-associated intradermal vascular proliferations, namely, KS, BA and multiple PGs are capable of both clinical and histological overlap. ${ }^{94}$ Skin biopsies from such cases must be carefully evaluated with this differential diagnosis in mind. Although histopathologists are familiar with the histopathology of typical patch, plaque (fig 6C) and nodular lesions of KS, it is important to remember that biopsies may occasionally reveal one of the uncommon variants of this AIDS-defining tumour.

Unusual clinical variants of AIDS-associated KS include KS with large hyperpigmented patches resembling a fixed drug eruption, and KS with verrucous, hyperkeratotic lesions. ${ }^{94}$ Biopsies from verrucous KS lesions show epidermal acanthosis, papillomatosis and hyperkeratosis, usually in association with

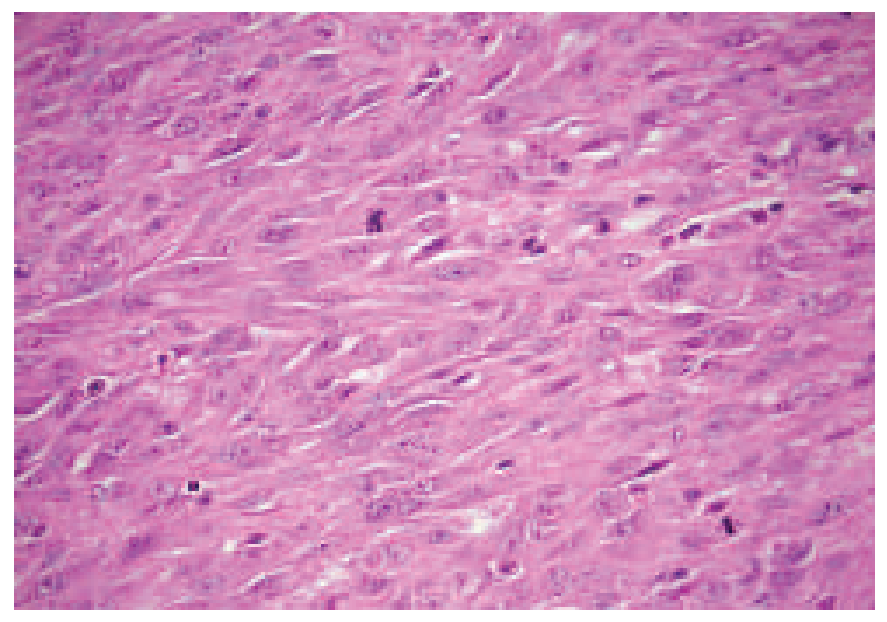

Figure 19 Anaplastic (pleomorphic) variant of AIDS-associated Kaposi sarcoma. Note the fascicles of mitotically active atypical spindled cells, with little evidence to suggest a vasoformative neoplasm.

plaque stage $\mathrm{KS}$ in the dermis (fig 17). The uncommon "lymphangiomatous" (lymphangioma-like) variant of KS represents a patch or plaque stage KS with irregular, ectatic, interanastomosing vascular channels, which dissect the dermal collagen bundles. Consequently, the histological appearance is reminiscent of a lymphatic tumour, especially benign lymphangioendothelioma/acquired progressive lymphangioma). ${ }^{95-98}$ The so-called promontory sign tends to be particularly prominent in this variant (fig 18). Overlying verrucous epidermal changes may supervene, especially in cases associated with chronic lymphoedema. Keloidal, ecchymotic and telangiectatic variants of KS have also been described..$^{89}$ The exceedingly uncommon anaplastic or pleomorphic variant of KS was first recognised in the context of classic and African endemic KS. ${ }^{100}{ }^{101}$ Rare cases of AIDS-associated nodular KS, however, may also exhibit anaplastic morphology (fig 19). ${ }^{102}$ The latter is discussed further in the section on spindle cell proliferations below.

The author has encountered rare examples of nodular KS in which part of the intradermal vascular proliferation may assume an unusual glomeruloid morphology, potentially mimicking glomeruloid haemangioma, tufted angioma (angioblastoma) or even reactive angioendotheliomatosis. Accurate diagnosis of these lesser-known variants of KS hinges on recognition of more typical KS areas in the biopsy, provided that the specimen is representative. The detection of human herpes virus type 8 (HHV-8) by immunohistochemical and/or PCR techniques is invaluable in problematic cases. ${ }^{94}$

Regression (involution) of KS skin lesions may occur in AIDS patients receiving HAART or chemotherapeutic agents such as paclitaxel or the angiogenesis inhibitor Col-3. ${ }^{103}$ Biopsies from these involuting cutaneous lesions reveal a rather subtle residual perivascular and peri-adnexal capillary proliferation (fig 20). A residual interstitial spindle cell proliferation dissecting dermal collagen bundles is usually absent in completely regressed lesions. A useful clue to the diagnosis is a prominent perivascular lymphoplamacytic infiltrate and abundant dermal siderophages. ${ }^{103}$ Deep dermal plasmacytosis, similar to that seen in secondary syphilis, may also be encountered. ${ }^{94}$

BA, a vasoproliferative lesion attributable to infection with Bartonella henselae and less commonly, B quintana, often presents with dozens of blood red, smooth surfaced cutaneous papules. ${ }^{104}$ Individual lesions may closely resemble $\mathrm{KS}$ or pyogenic granuloma. ${ }^{44}$ Skin biopsy plays an essential role in the diagnosis of this 


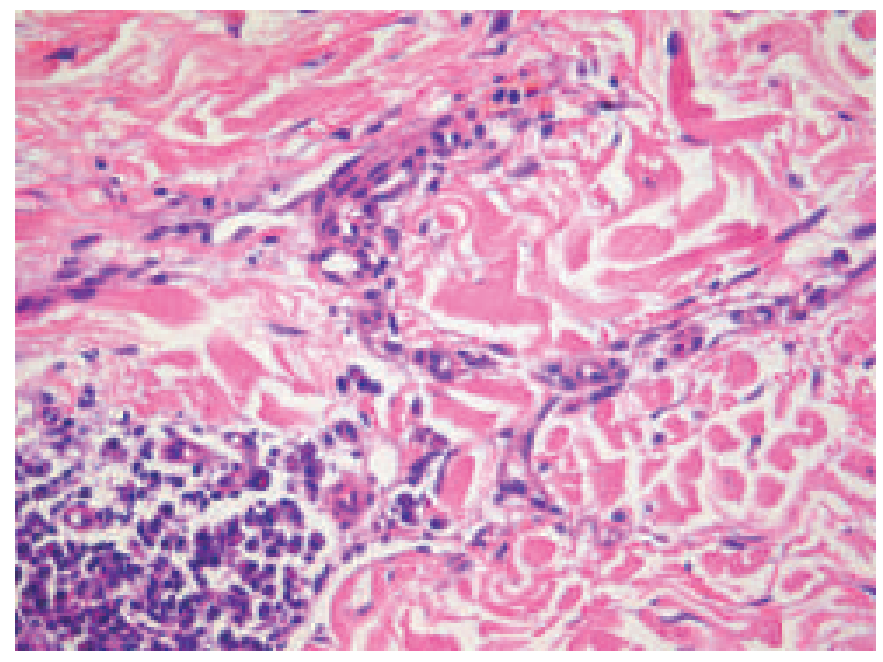

Figure 20 Involuting Kaposi sarcoma following 19 months of highly active antiretroviral therapy (HAART). There is a subtle perivascular capillary proliferation accompanied by a prominent contingent of plasma cells.

treatable opportunistic infectious disease. In addition to a vaguely lobulated intradermal proliferation of capillaries lined by plump, epithelioid endothelial cells, there are aggregates of polymorphonuclear leucocytes, with karyorrhectic debris and amphophilic extracellular aggregates of bacillary organisms in the intervening stroma. ${ }^{4} 104{ }^{105}$ Rarely, BA is associated with pseudoepitheliomatous hyperplasia. ${ }^{106}$ WS staining will highlight the clumps of Bartonella organisms. The bacteria have a characteristic ultrastructural appearance. PCR may also confirm the diagnosis. ${ }^{49}$

PG is an important differential diagnosis of BA, especially when a superficial polypoid BA lesion has an epidermal collarette (fig 21). A WS stain should be performed if there is the remotest suspicion of BA. Biopsies of all suspected "PGs" in patients who reside in areas with a high prevalence of AIDS should always be carefully scrutinised for possible evidence of BA. ${ }^{94}$ A regressing BA lesion may closely resemble an involuting PG. The pathologist might not consider a diagnosis of BA in these cases, as the biopsy will reveal a paucity of dermal inflammation and an absence of recognisable Bartonella colonies in regressing lesions. Instead, there is an increase in dermal blood vessel density and separation of the vascular component by a somewhat sclerotic stroma (fig 22). ${ }^{94} \mathrm{~A}$ high index of suspicion is therefore required. A history of prior administration of antimicrobial agents and knowledge of the HIV status may prove invaluable. It has been the author's experience that the diagnosis can often only be confirmed in such cases by performing PCR for Bartonella species.

In the majority of cases, $\mathrm{KS}$ is an important clinical differential diagnosis of BA rather than a histological one. Rare biopsies of otherwise typical BA cases, however, may reveal Kaposiform areas at the periphery ${ }^{94}$ Absence of detectable HHV-8 by immunohistochemistry or PCR is helpful in such cases. ${ }^{107}$ It is nevertheless worth noting that rare cases of BA with concurrent KS have been documented. ${ }^{108}$ Immunohistochemical markers of endothelial differentiation, such as CD34 and CD31, will not facilitate distinction between $\mathrm{BA}$ and $\mathrm{KS}$. Other theoretical mimics of BA include verruga peruana, epithelioid haemangioma and eruptive haemangioendothelioma; however, none of the aforementioned conditions has an association with HIV infection/AIDS. ${ }^{4} 109$
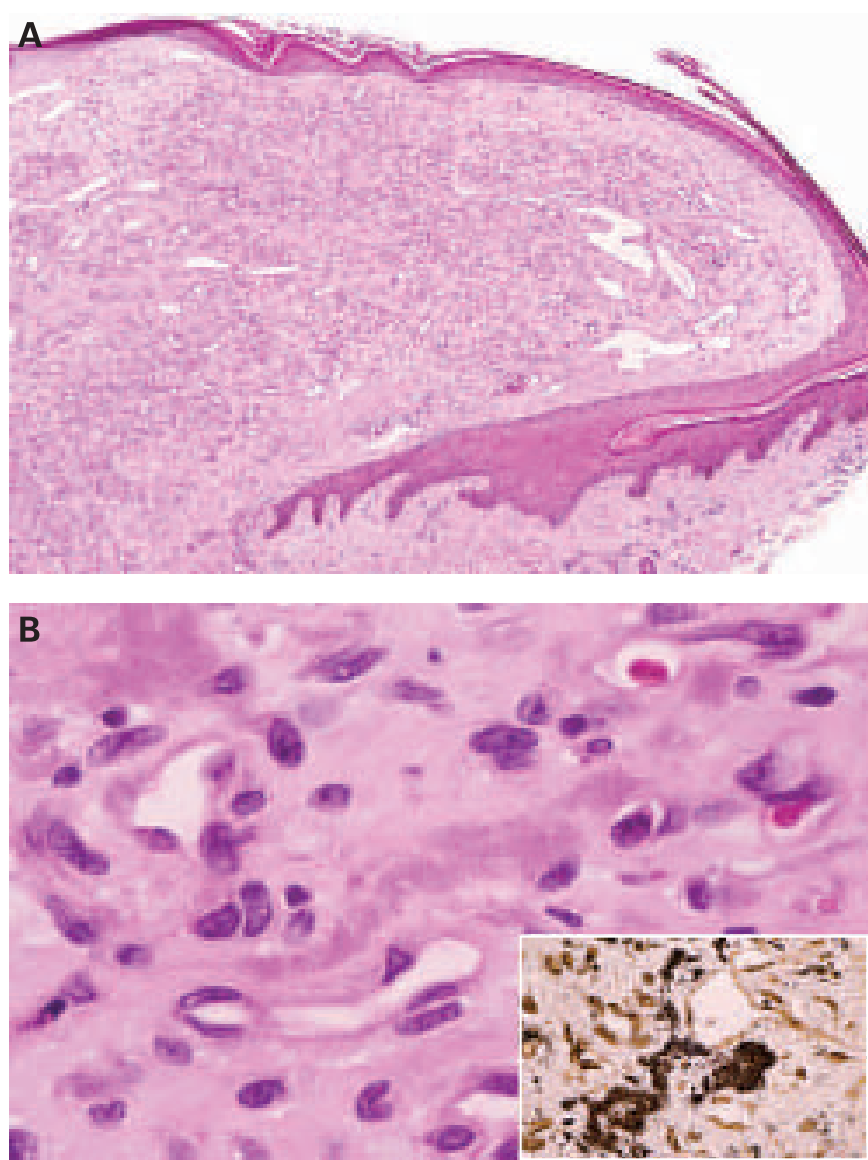

Figure 21 (A) Biopsy of a small lesion of bacillary angiomatosis, emphasising the pyogenic granuloma-like architecture in this example. (B) Amphophilic extracellular aggregates of Bartonella bacilli, whose presence was confirmed by Warthin-Starry staining (inset).

There have been a number of recent reports of multiple PGs arising in patients (including children) treated with the HIV protease inhibitor, indinavir. ${ }^{20-22}$ Since these PGs characteristically arise on the toes and are often associated with paronychia of the affected digits, knowledge of the exact site of lesion (and the fact that the patient is receiving HAART) is essential when evaluating

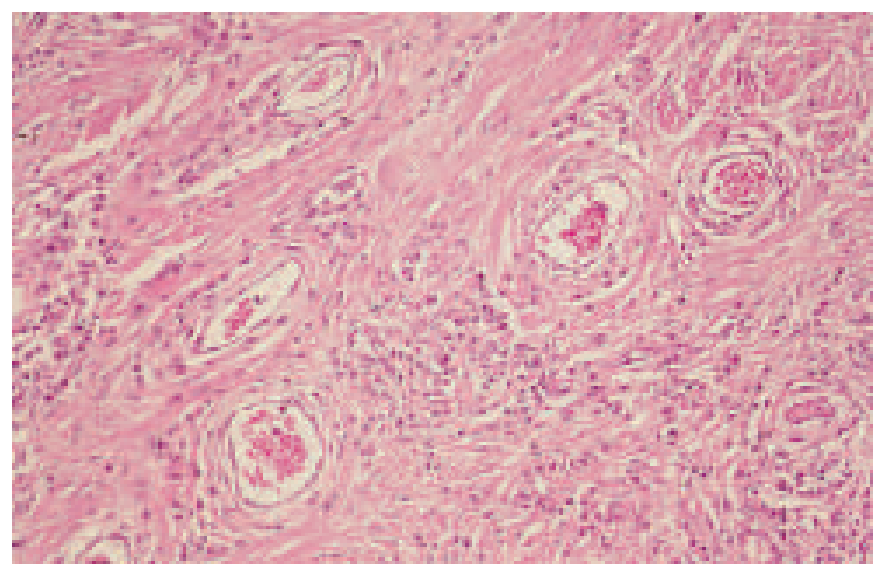

Figure 22 Regressing bacillary angiomatosis. Instead of the usual proliferation of small capillaries and intervening neutrophilic infiltration, this medium-power view of the deeper part of the lesion shows interstitial fibrosis and vessels of a relatively large calibre. Bartonella DNA was detected by PCR. 


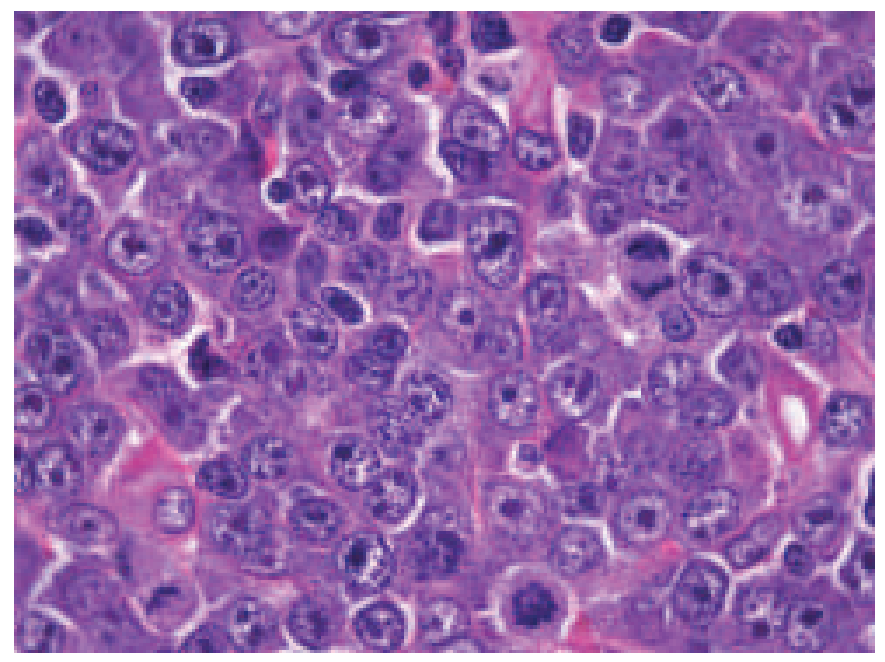

Figure 23 AIDS-associated diffuse large B-cell lymphoma, plasmablastic type.

biopsies from such lesions. Acral involvement by BA is an important diagnostic consideration on biopsy, especially if there is bacterial colonisation and neutrophilic infiltration of an ulcerated PG. True examples of eruptive PG have not been described in the context of HIV infection/AIDS; AIDS patients with "eruptive PGs" inevitably have BA on further investigation.

Superficial shave biopsies from HIV-associated vascular proliferations should be discouraged, as they are often not sufficiently representative of the lesion. In verrucous or ulcerated $\mathrm{KS}$, for example, the KS lesion is either not included in the specimen or there is only scant representation of the most superficial and often non-diagnostic aspect thereof. In extensively ulcerated lesions, most of the shave biopsy is occupied by inflamed granulation tissue in response to the exudate. Any subtle spindle proliferation at the base of the biopsy is easily overlooked when the KS component merges with the overlying granulation tissue. ${ }^{94}$

\section{Spindle cell proliferations}

The differential diagnosis of HIV-associated dermal spindle cell proliferations includes nodular $\mathrm{KS}$ and multiple eruptive dermatofibromas (MED). ${ }^{94110111}$ Unlike the former, the latter is not associated with detectable HHV-8 infection. ${ }^{112}{ }^{113}$ Before entertaining a diagnosis of MED, it is essential that cutaneous involvement by leishmaniasis is excluded. ${ }^{114}{ }^{115}$ A Giemsa stain will highlight the intracytoplasmic Leishmania organisms in these cases. ${ }^{4}$ The anaplastic or pleomorphic variant of AIDSassociated KS is exceedingly rare, and comprises mitotically active spindled cells with marked nuclear atypia (fig 19). ${ }^{102}$ In biopsy material, this variant must be distinguished from other malignant spindle cell neoplasms, especially angiosarcoma, leiomyosarcoma, fibrosarcomatous dermatofibrosarcoma protuberans and amelanotic spindle cell melanoma; this is facilitated by appropriate immunohistochemistry. ${ }^{94}$

\section{Atypical lymphoid infiltrates}

The first step in assessing biopsy material from such cases is to determine if the infiltrate is dermal or primarily epidermotropic. Epidermotropic T-cell infiltrates in HIV-infected individuals are only occasionally encountered. It is worth noting that mycosis fungoides (MF) is exceedingly rare in this patient population. ${ }^{116}$ An uncommon benign epidermotropic CD8+ T-cell infiltrate
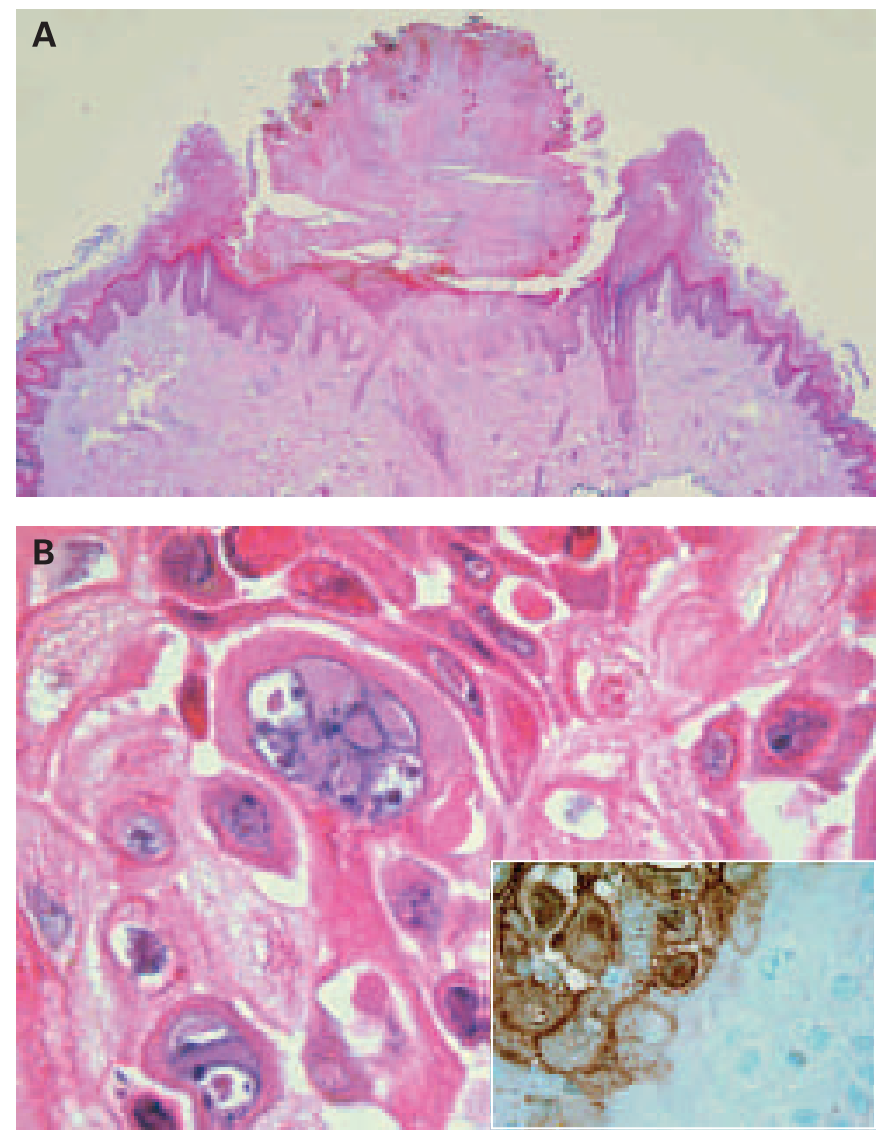

Figure 24 (A) Hyperkeratotic herpes zoster. (B) Multinucleated epidermal keratinocytes harbouring intranuclear varicella zoster virus inclusions, whose presence was confirmed by immunohistochemistry (inset).

closely resembling MF both clinically and pathologically, however, has been reported in $\mathrm{HIV}+$ patients. ${ }^{117-120}$ Immunohistochemistry and T-cell receptor (TCR) gene rearrangement studies are essential in such cases. The atypical lymphoid cells in MF are typically CD4+, CD8-, CD2-, and are clonal, whereas the HIV-associated epidermotropic CD8+ infiltrate (also referred to as pseudo-Sézary syndrome) is CD2+, CD4-, CD8+, and is polyclonal on TCR gene rearrangement studies. ${ }^{117-121}$

Dermal-based atypical lymphoid infiltrates may be either reactive or neoplastic. NHL occurring in an HIV+ patient is AIDSdefining. ${ }^{88} 116$ Although AIDS-associated NHLs may rarely arise primarily in the skin, most cases represent secondary cutaneous dissemination by a nodal or visceral NHL. ${ }^{88} 116$ The spectrum of Bcell neoplasms includes diffuse large B-cell lymphoma (DLBL), Burkitt/Burkitt-like lymphoma and plasmablastic lymphoma (PBL), a variant of DLBL (fig 23)..$^{81} 116$ 122-124 Recently, HHV-8 and Epstein-Barr virus (EBV) have been implicated in the pathogenesis of $\mathrm{PBL}{ }^{122-124}$ Biopsies from nodular lesions of secondary syphilis may show a dense, pleomorphic B-cell rich dermal lymphoid infiltrate that closely simulates a B-cell NHL. ${ }^{125} 126$ The presence of conspicuous numbers of admixed plasma cells is a useful clue to the diagnosis. ${ }^{125} 126$

T-cell NHLs (such as CD30+ anaplastic large cell lymphoma) are uncommon and may require the use of second line anti-Tcell antibodies for diagnosis when epitopes such as CD3 are no longer expressed in the dermal lymphoid infiltrate. ${ }^{88}$ Serial 


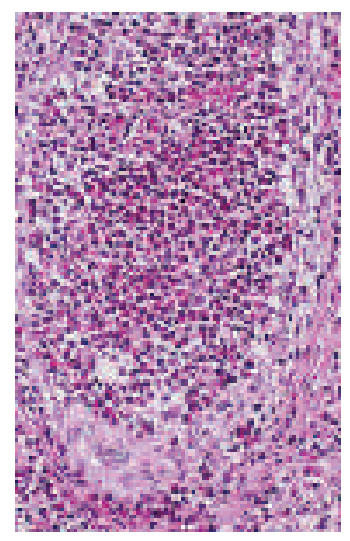

Figure 25 HIV-associated eosinophilic folliculitis. Many serial sections may be required to demonstrate the folliculocentric infiltrate of eosinophilic leucocytes, and hence facilitate distinction from HIV-associated papulopruritic eruption.

sections should always be examined to exclude molluscum contagiosum when a biopsy reveals an atypical CD30+ T-cell infiltrate, as the perilesional dermal lymphoid infiltrate occurring in this condition may closely mimic a CD30+ cutaneous lymphoproliferative disorder. ${ }^{4}$

The basic immunohistochemical panel should include antibodies to CD45, CD3, CD30 and CD20; this should be expanded to include markers such as CD79a, epithelial membrane antigen, VS38c, CD138 and anti-HHV-8 in those cases where PBL is suspected. In situ hybridisation studies are required for detection of EBV-encoded mRNA. ${ }^{124}$

\section{Verrucous/hyperkeratotic lesions}

Accurate clinicopathological correlation is important when a skin biopsy from an HIV+ patient shows an epidermis with marked verrucous hyperplasia and hyperkeratosis. Sections should be examined for features of the following conditions: verruca vulgaris, hyperkeratotic herpes zoster (fig 24), Norwegian scabies, chronic mucocutaneous candidiasis, rupial secondary syphilis, and verrucous KS (fig 17). ${ }^{343394127-129}$ Diagnosis of the last condition may not be possible in shave biopsies that are too superficial. Biopsies from epidermodysplasia verruciformis-like lesions reveal acanthosis, hyperkeratosis, and swollen, pale grey keratinocytes with cytoplasmic vacuolation. ${ }^{4}$ True verrucous hyperplasia, however, is seldom encountered.

\section{Syringotropic neutrophilic infiltration}

The presence of a polymorphonuclear leucocytic infiltrate centred on the sweat glands suggests neutrophilic eccrine hidradenitis (NEH). ${ }^{130}$ This condition is usually attributable to zidovudine therapy and tends to affect eccrine sweat gland coils, with epithelial degeneration and luminal distension by neutrophils, and an absence of hair follicle involvement. ${ }^{130}$ Hidradenitis suppurtiva occurs in sites rich in apocrine or apoeccrine glands (eg axillae, groins). The latter condition, however, is primarily a follicular disorder in which secondary neutrophilic infiltration into the sweat gland coils is sometimes encountered; this may potentially result in confusion with $\mathrm{NEH} .{ }^{46}$

\section{Biopsy findings in miscellaneous clinical settings}

The biopsy findings in erythrodermic HIV+ patients vary according to the aetiology. Adverse drug reactions are a common cause of erythroderma; the antituberculous drug, ethambutol was the agent implicated most frequently in one study. ${ }^{131}$ Biopsies from such cases may exhibit a combination of spongiotic, lichenoid and lymphocytic vasculopathic reactions, often with eosinophils amidst the dermal inflammatory infiltrate. Other potential causes of erythroderma in this clinical

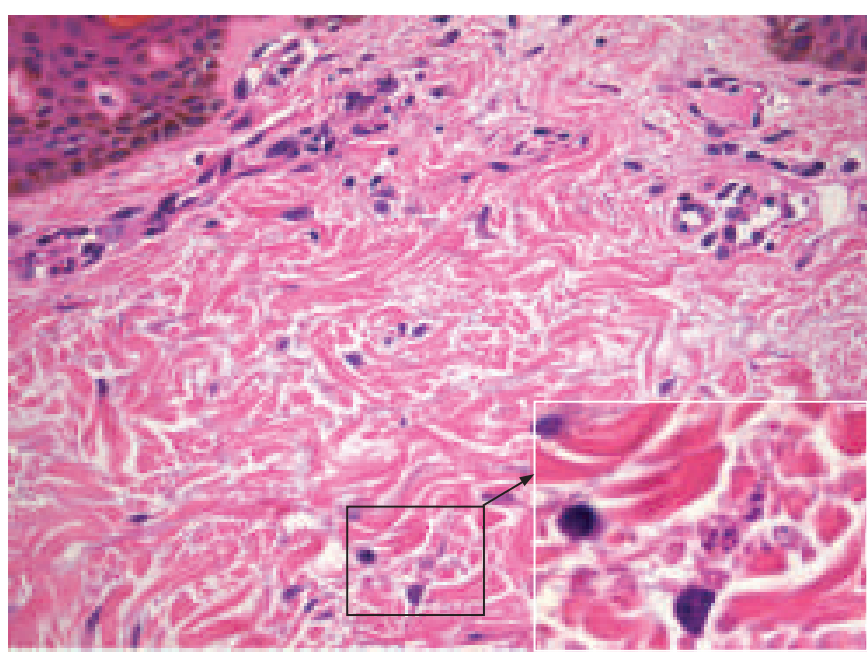

Figure 26 Skin biopsy from a profoundly immunosuppressed patient with AIDS-associated histoplasmosis. The dermal host response is negligible despite the presence of numerous Histoplasma capsulatum spores (inset).

context include SD (fig 7), psoriasis, PRP (fig 8) and the HIVassociated epidermotropic CD8+ infiltrate.

Papular follicular eruptions are common in HIV+ individuals. Pruritus is a frequent presenting symptom. ${ }^{43}$ Causes include acute suppurative (bacterial) folliculitis, HIV-associated eosinophilic folliculitis (HIV-EF) (fig 25), Pityrosporum folliculitis, necrotising folliculitis and the pruritic papular (papulopruritic) eruption (PPE) of HIV infection. ${ }^{43} 132$ Although an eosinophilic pustular reaction is almost invariably indicative of HIV-EF, it is worth remembering that certain fungal infections of the hair shaft may rarely manifest with eosinophilic folliculitis. ${ }^{133}$

Papular mucinosis is a rarer cause for a papular eruption in HIV/AIDS. ${ }^{134} 135$ Alcian blue staining will readily confirm the presence of interstitial mucin deposition in the dermis in such cases. Interestingly, biopsies may show an associated eczematous dermatitis. ${ }^{135}$ There have also been rare reports of scleroedema and reticular erythematous mucinosis occurring in patients with HIV/AIDS. ${ }^{134} 136$

Xerosis may be a presenting sign of AIDS. ${ }^{28}{ }^{137}$ A skin biopsy will usually reveal a combination of alterations, including acanthosis, mild hyperkeratosis, parakeratosis, focal spongiosis and sometimes a perivascular lymphocytic infiltrate. Correlation with the clinical findings is important as this constellation of features could also be encountered in eczema. Biopsies occasionally exhibit accompanying features of acquired ichthyosis, namely, marked hyperkeratosis in the presence of a diminished epidermal granular layer. ${ }^{4}{ }^{138}$

\section{The "normal" or "near-normal" biopsy}

Certain dermatological conditions may present with very subtle histological alterations. Diseases to consider include a superficial fungal infection, PRP, the interstitial (or so-called incomplete) form of GA, an early patch stage lesion of $\mathrm{KS}$, and anetoderma. ${ }^{4} 293094$ 139-142 The histopathologist must therefore be guided by the clinical features and the clinical differential diagnosis. An elastic tissue stain is required for confirmation of a diagnosis of anetoderma, and in these cases it is important to alert the dermatologist to the potential presence of anticardiolipin antibodies. ${ }^{141} 142$

Profoundly immunosuppressed individuals often are unable to mount a satisfactory inflammatory response to certain 


\section{Take-home messages}

- Histopathologists practising in regions of the world where HIV/ AIDS is prevalent must be familiar with the diverse spectrum of HIV-related cutaneous pathology.

- There should be a high index of suspicion for HIV-related skin pathology if a biopsy is obtained from a patient whose skin disease has an atypical clinical presentation, or if that disease has failed to respond to conventional therapy.

- Skin biopsy material from HIV+ patients should always be carefully examined for more than one pathological process.

- The possibility of an adverse drug reaction should always be considered, especially if a biopsy shows a combination of reaction patterns.

- The liberal use of serial sections, special stains for infective microorganisms, appropriate immunohistochemical stains and molecular studies is crucial for accurate diagnosis.

- Additional biopsies should be recommended for microbiological confirmation of an infective disorder, or if more than one disease is suspected clinically.

- Superficial shave biopsies should be discouraged as pathology centred on the deeper dermis (or subcutis) is often missed in such specimens.

- As with dermatopathology in general, careful clinicopathological correlation is of paramount importance.

opportunistic pathogens. Figure 26 illustrates an example of AIDS-associated histoplasmosis in which the dermis harbours numerous fungal organisms, yet the host's reaction to the infection is almost negligible.

\section{Dual pathology or multiple pathologies}

A critically important aspect of examining biopsy material from HIV+ patients is the careful histopathological examination for more than one pathological process. Staphylococcal infections frequently complicate pre-existing dermatoses, especially when associated with pruritus and excoriation (eg SD, scabies, etc). Once one opportunistic infection has been diagnosed, it is always wise to carefully examine that biopsy for one or more additional opportunistic pathogens and/or concomitant KS, or vice versa. Figure 6 illustrates how a single punch biopsy from a patient with AIDS may harbour multiple pathological lesions.

Acknowledgements: The author gratefully acknowledges Mr Eric Liebenberg, Division of Anatomical Pathology, University of the Witwatersrand, Johannesburg for his assistance with the photomicrography.

Competing interests: None.

Patient consent: Informed consent was not received for the publication of figure 1 .

\section{REFERENCES}

1. UNAIDS. 2006 Report on the global AIDS epidemic. http//:www.UNAIDS.org (accessed 6 March 2008).

2. Hartshorne S. Dermatological disorders in Johannesburg, South Africa. Clin Exp Dermatol 2003;28:661-5.

3. Johnson RA. Cutaneous manifestations of human immunodeficiency virus disease In: Freedberg IM, Eisen AZ, Wolff K, Austen KF, Goldsmith LA, Katz SI, eds Fitzpatrick's dermatology in general medicine, 6th edn. New York: McGraw-Hill, 2003:2138-50.

4. Grayson W, Calonje E, McKee PH. Infectious diseases of the skin. In: McKee PH, Calonje E, Granter SR, eds. Pathology of the skin with clinical correlations, 3rd edn. Philadelphia: Elsevier Mosby, 2005:837-992.

5. Myskowski PI, Ahkami R. Dermatologic complications of HIV infections. Med Clin North Am 1996:80:1415-35.
6. Schonwetter RS, Nelson EB. Alopecia areata and the acquired immunodeficiency syndrome-related complex. Ann Int Med 1986;104:287.

7. Cockerell CJ. Cutaneous manifestations of HIV infection other than Kaposi's sarcoma: clinical and histologic aspects. J Am Acad Dermatol 1990:22:1260-9.

8. Dijkstra JWE. Histoplasmosis. Dermatol Clin 1989;7:251-7.

9. Welykyj S, von Heimburg A, Massa MC, et al. Cutaneous lesions of histoplasmosis with transepidermal elimination in a patient with acquired immunodeficiency syndrome. Cutis 1991;47:397-400.

10. Laochumroonvorapong $\mathbf{P}$, DiCostanzo DP, $\mathrm{Wu} \mathrm{H}$, et al. Disseminated histoplasmosis presenting as pyoderma gangrenosum-like lesions in a patient with acquired immunodeficiency syndrome. Int J Dermatol 2001;40:518-21.

11. Stong GC, Raval HB, Martin JW, et al. Nodular subcutaneous histoplasmosis. A case report with diagnosis by fine needle aspiration biopsy. Acta Cytol 1994;38:777-81.

12. Carr A, Cooper DA. Adverse effects of antiretroviral therapy. Lancet 2000;356:1423

13. Ward HA, Russo GG, Shrum J. Cutaneous manifestations of antiretroviral therapy J Am Acad Dermatol 2002;46:284-93.

14. Calista D, Morri M, Stagno A, et al. Changing morbidity of cutaneous diseases in patients with HIV after the introduction of highly active antiretroviral therapy including a protease inhibitor. Am J Clin Dermatol 2002;3:59-62.

15. Rotunda A, Hirsch RJ, Scheinfeld N et al. Severe cutaneous reaction associated with the use of human immunodeficiency virus medications. Acta Derm Venereol 2003;83:1-9.

16. Nelson AM. The pathology induced by modern anti-retroviral therapy against HIV. Histopathology 2002;41(Suppl 2):73-6.

17. Smith KJ, Skelton HJ, Yeager J, et al. Increased drug reactions in HIV-1-positive patients: a possible explanation based on patterns of immune dysregulation seen in HIV-1 disease. The Military Medical Consortium for the Advancement of Retroviral Research (MMCARR). Clin Exp Dermatol 1997:22:118-23.

18. Warren KJ, Boxwell DE, Kim NY, et al. Nevirapine-associated Stevens-Johnson syndrome. Lancet 1998;351:567.

19. Mosam A, Dawood H. Antiretroviral therapy and the skin. S Afr Dermatol Rev 2005;5:26-33

20. Calista D, Boschini A. Cutaneous side effects induced by indinavir. Eur J Dermatol 2000;10:292-6

21. Sass J0, Jakob-Solder B, Heitger A, et al. Paronychia with pyogenic granuloma in a child treated with indinavir: the retinoid-mediated side effect theory revisited. Dermatology 2000;200:40-2.

22. Bouscarat F, Bouchard C, Bouhour D. Paronychia and pyogenic granuloma of the great toes in patients treated with indinavir. N Engl J Med 1998;338:1776-7.

23. Lipman M, Breen R. Immune reconstitution inflammatory syndrome in HIV. Curr Opin Infect Dis 2006:19:20-5.

24. LeBoit P. Dermatopathologic findings in patients infected with HIV. Dermatol Clin 1992;10:59-71.

25. Smith KJ, Skelton HG, Angritt P. Histopathologic features of HIV-associated skin disease. Dermatol Clin 1991:9:551-78.

26. Soeprono FF, Scinella RA Cockerall CJ et al. Seborrheic-like dermatitis of acquired immunodeficiency syndrome. J Am Acad Dermatol 1986;14:242-8.

27. Herman $\mathbf{K L}$, Jacoby RA, Webster G. Pathology of HIV-related skin disease. Dermatol Clin 1991:9:91-105.

28. Sadick NS, McNutt S, Kaplan MH. Papulosquamous dermatoses of AIDS. J Am Acad Dermatol 1990:22:1270-7.

29. Blauvelt A, Nahass GT, Pardo RJ, et al. Pityriasis rubra pilaris and HIV infection. J Am Acad Dermatol 1991;24:703-5.

30. Miralles ES, Núñez M, De Las Heras ME, et al. Pityriasis rubra pilaris and human immunodeficiency virus. Br J Dermatol 1995;133:990-3.

31. Calonje E, Neill S. Diseases of the genital skin: syphilis. In: McKee PH, Calonje E, Granter SR, eds. Pathology of the skin with clinical correlations, 3rd edn. Philadelphia: Elsevier Mosby, 2005:494-502.

32. Radolf JD, Kaplan RP. Unusual manifestations of secondary syphilis and abnorma humoral response to Treponema pallidum infection antigens in a homosexual man with asymptomatic human immunodeficiency virus infection. J Am Acad Dermatol 1988;18:423-8.

33. Gregory N, Sanchez M, Buchness MR. The spectrum of syphilis in patients with human immunodeficiency virus infection. J Am Acad Dermatol 1990;22:1061-7.

34. Tosca A, Stavropoulos PG, Hatziolou E, et al. Malignant syphilis in HIV-infected patients. Int J Dermatol 1990;29:575-8.

35. Don PC, Rubenstein R, Christie S. Malignant syphilis (lues maligna) and concurrent infection with HIV. Int J Dermatol 1995;34:403-7.

36. Reichel M, Mauro TM, Ziboh VA, et al. Acrodermatitis enteropathica in a patient with the acquired immunodeficiency syndrome. Arch Dermatol 1992:128:415-7.

37. Meola T, Sanchez M, Lim HW, et al. Chronic actinic dermatitis associated with human immunodeficiency virus infection. Int J Dermatol 1997:137:431-6.

38. Rico MJ, Kory WP, Gould EW, et al. Interface dermatitis in patients with the acquired immunodeficiency syndrome. J Am Acad Dermatol 1987;16:1209-18.

39. Zelickson BD, Muller SA. Generalized pustular psoriasis. Arch Dermatol 1991;127:1339-44.

40. Winchester R, Bernstein DH, Fischer HD et al. The co-occurrence of Reiter's syndrome and acquired immunodeficiency. Ann Int Med 1987;106:19-26.

41. Sawhney RA, Dubin DB, Otley CC, et al. Generalized exanthematous pustulosis induced by medications. Int J Dermatol 1996:35:826-7. 
42. Burrows NP, Russell-Jones R. Pustular drug eruptions: histological spectrum. Histopathology 1993;22:569-73.

43. Budavari JM, Grayson W. Papular follicular eruptions in HIV-positive patients in South Africa. Int J Dermatol 2007;46:706-10.

44. Aly R, Bibel DJ, Conant M, et al. The cutaneous microbiology of HIV+ patients. Carriage of Staphylococcus aureus and Candida albicans. J Invest Dermatol 1990;94:503A.

45. Crespo-Erchiga V, Delgado Florencio V. Malassezia species in skin diseases. Curr Opin Infect Dis 2002;15:133-42.

46. Resnik SD, Murrell DF, Woosley J. Acne conglobata and a generalized lichen spinulosis-like eruption in a man seropositive for human immunodeficiency virus. J Am Acad Dermatol 1992;26:1013-4.

47. Murakawa GJ, Kerschmann R, Berger T. Cutaneous cryptococcus infection and AIDS: report of 12 cases and review of the literature. Arch Dermatol 1996;132:545-8.

48. Narisawa Y, Kojima T, Iriki A, et al. Tissue changes in cryptococcosis: alteration from gelatinous to suppurative inflammatory response with asteroid body. Mycopathologia 1989;106:113-9.

49. Quimby SR, Connolly SM, Winkelmann RK, et al. Clinicopathologic spectrum of specific cutaneous lesions of disseminated coccidiodomycosis. J Am Acad Dermatol 1992:26:79-85

50. Prichard JG, Sorotzkin RA, James RE 3rd. Cutaneous manifestations of disseminated coccidiodomycosis in the acquired immunodeficiency syndrome. Cutis 1987;39:203-5.

51. Witzig RS, Hoadley DJ, Greer DL, et al. Blastomycosis and acquired immunodeficiency syndrome: three new cases and review. South Med J 1994;87:715-9.

52. Al-Tawfiq JA, Wools KK. Disseminated sporotrichosis and Sporotrichosis schenkii fungemia as the initial presentation of human immunodeficiency virus infection. Clin Infect Dis 1998;26:1403-6.

53. Daikos GL, Uttamchandani RB, Tuda C, et al. Disseminated miliary tuberculosis of the skin in patients with AIDS: report of four cases. Clin Infect Dis 1998;27:205-8.

54. Bartalot R, Pujol RM, Garcia-Patos V, et al. Cutaneous infections due to nontuberculous mycobacteria: histopathological review of 28 cases. J Cutan Pathol 2000;27:124-9.

55. Hale MJ. Mycobacterial infection: a histopathological chameleon. Curr Diagn Pathol 2000;6:93-102

56. Stellbrink HJ, Koperski K, Albrecht $\mathrm{H}$, et al. Mycobacterium kansasii infection limited to skin and lymph node in a patient with AIDS. Clin Exp Dermatol 1990;15:457-8.

57. Toth IR, Kazal HL. Botryomycosis in acquired immunodeficiency syndrome. Arch Pathol Lab Med 1987;111:246-9.

58. Salvemini JN, Baldwin HE. Botryomycosis in a patient with acquired immunodeficiency syndrome. Cutis 1995;56:158-60.

59. Carlson JA, Ng BT, Chen K-R. Cutaneous vasculitis update: diagnostic criteria, classification, epidemiology, etiology, pathogenesis, evaluation and prognosis. Am J Dermatopathol 2005;27:504-28.

60. Chetty R. Vasculitides associated with HIV infection. J Clin Pathol 2001;54:275-8.

61. Potashner W, Buskila D, Patterson B, et al. Leukocytoclastic vasculitis with HIV infection. J Rheumatol 1990;17:1104-7.

62. McSorely J, Shapiro L, Brownstein MH, et al. Herpes simplex and varicella-zoster: comparative histopathology of 77 cases. Int J Dermatol 1974;13:67-75.

63. Uhoda I, Pierard-Franchimont C, Pierard GE. Varicella-zoster virus vasculitis: a case of recurrent varicella without epidermal involvement. Dermatology 2000;200:173-5.

64. Calabrese LH. Vasculitis and infection with human immunodeficiency virus (HIV). Ann Intern Med 1991;17:131-47.

65. Martin JL, Dronda F, Cháves F. Erythema elevatum diutinum, a clinical entity to be considered in patients infected with HIV-1. Clin Exp Dermatol 2001;26:275-6.

66. Requena L, Sánchez Yus E, Martín L. Erythema elevatum diutinum in a patient with acquired immunodeficiency syndrome. Another clinical simulator of Kaposi's sarcoma. Arch Dermatol 1991;127:1819-22.

67. Gherardi R, Belec L, Mhiri C, et al. The spectrum of vasculitis in human immunodeficiency virus infected patients. A clinicopathologic evaluation. Arthritis Rheum 1993;36:1164-74.

68. Dimitrakopoulos AN, Kordossis T, Hatzakis T, et al. Mixed cryoglobulinemia in HIV-1 infection: the role of HIV-1. Ann Int Med 1999;130:226-30.

69. Morrison JGL, Fourie ED. The papulonecrotic tuberculide: from Arthus reaction to lupus vulgaris. Br J Dermatol 1974;91:263-700

70. Requena L, Farina C, Barat A. Degos disease in a patient with acquired immunodeficiency syndrome. J Am Acad Dermatol 1998;38:852-6.

71. Helton HJ, Loveless M, White CR Jr. Cutaneous acanthamoeba infection associated with leukocytoclastic vasculitis in an AIDS patient. Am J Dermatopathol 1993; 15:146-9.

72. Chu P, Connolly K, LeBoit PE. The histopathologic spectrum of palisaded neutrophilic and granulomatous vasculitis. Arch Dermatol 1994;130:1278-83.

73. Cooper LM, Patterson JAK. Allergic vasculitis and angiitis of Churg-Strauss. Case report in a patient with antibodies to human immunodeficiency virus and hepatitis $B$ virus. Int J Dermatol 1989;28:597-9.

74. Schneider JW, Jordaan HF. The histopathologic spectrum of erythema induratum of Bazin. Am J Dermatopathol 1997:19:323-33.

75. Narisawa Y, Koijima T, lriki A, et al. Tissue changes in cryptococcosis: histologic alteration from gelatinous to suppurative tissue response with asteroid body. Mycopathologica 1989:106:113-9.
76. Manfredi R, Mazzoni A, Nanetti A, et al. Morphologic features and clinical significance of skin involvement in patients with AIDS-related cryptococcosis. Acta Derm Venereol 1996; 76:72-4

77. McGregor JM, McGibbon. Disseminated granuloma annulare as a presentation of acquired immunodeficiency syndrome (AIDS). Clin Exp Dermatol 1992;17:60-2.

78. Bakos L, Hampe S, da Rocha JL, et al. Generalized granuloma annulare in a patient with acquired immunodeficiency syndrome (AIDS). J Am Acad Dermatol 1987:17:844-5

79. Huerter CJ, Baas J, Bergfield WE, et al. Perforating granuloma annulare in a patient with acquired immunodeficiency syndrome (AIDS). Arch Dermatol 1987;123:1217-70.

80. Weinberg JM, Mysliwiec A, Turiansky GW, et al. Viral folliculitis. Atypical presentations of herpes simplex, herpes zoster, and molluscum contagiosum. Arch Dermatol 1997;133:983-6.

81. Smith KJ, Skelton HG 3rd, James WD, et al. Concurrent epidermal involvement of cytomegalovirus and herpes simplex virus in two HIV-infected patients. Military Medical Consortium for Applied Retroviral Research (MMCARR). J Am Acad Dermatol 1991;25:500-6.

82. Ramdial PK, Dlova NC, Sydney C. Cytomegalovirus neuritis in perineal ulcers. $J$ Cutan Pathol 2002;29:439-44.

83. Chetty R, Bramdev A, Govender D. Cytomegalovirus-induced syringosquamous metaplasia. Am J Dermatopathol 1999;21:487-90.

84. Gonzalez-Beato MJ, Moyano B, Sanchez C, et al. Kaposi's sarcoma-like lesions and other nodules as cutaneous involvement in AIDS-related visceral leishmaniasis. Br J Dermatol 2000;143:1316-8.

85. Bumb RA, Mehta RD. Amoebiasis cutis in HIV positive patient. Indian J Dermatol Venereol Leprol 2006; 12:224-6.

86. Tan B, Weldon-Linne CM, Rhone DP, et al. Acanthamoeba infection presenting as skin lesions in patients with the acquired immunodeficiency syndrome. Arch Pathol Lab Med 1993;117:1043-6.

87. Schwartz RA. Kaposi's sarcoma: an update. J Surg Oncol 2004;87:146-51.

88. Carbone A. AIDS-related non-Hodgkin's lymphomas: from pathology and molecular pathogenesis to treatment. Hum Pathol 2002;33:392-404.

89. Kreuter A, Gambichler T, Hoffmann K, et al. Association of HIV infection, pyoderma gangrenosum and psoriasis. Acta Derm Venereol 2002;82:150-2.

90. Cohen PR, Grossman ME. Clinical features of human immunodeficiency virusassociated disseminated herpes zoster virus infection-a review of the literature. Clin Exp Dermatol 1991;14:273-6.

91. Davis MDP, Dinneen AM, Landa N, et al. Grover's disease: clinicopathologic review of 72 cases. Mayo Clin Proc 1999;74:229-34.

92. Kaplan RP, Callen JP. Pemphigus associated diseases and induced pemphigus. Clin Dermatol 1983;1:42-71.

93. Conrad ME. AIDS and porphyria cutanea tarda. Am J Hematol 1988;28:207-8.

94. Grayson W. A re-appraisal of vascular proliferations in human immunodeficiency virus infected patients. S Afr Dermatol Rev 2006;6:48-57.

95. Ramirez JA, Laskin WB, Guirart J. Lymphangioma-like Kaposi sarcoma. J Cutan Pathol 2005; 32:286-92.

96. Cossu S, Satta R, Cottoni F, et al. Lymphangioma-like variant of Kaposi's sarcoma: clinicopathologic study of seven cases with review of the literature. Am J Dermatopathol 1997;19:16-22.

97. Gange RW, Jones EW. Lymphangioma-like variant of Kaposi's sarcoma. A report of three cases. Br J Dermatol 1979;100:327-34.

98. Guillou L, Fletcher CD. Benign lymphangioendothelioma lacquired progressive lymphangioma): a lesion not to be confused with well-differentiated angiosarcoma and patch stage Kaposi's sarcoma: clinicopathologic analysis of a series. Am J Surg Pathol 2000:24:1047-57.

99. Schwartz RA, Spicer MS, Janniger CK, et al. Keloidal Kaposi's sarcoma: report of three patients. Dermatology 1994;189:271-4.

100. Satta R, Cossu S, Massarelli G, et al. Anaplastic transformation of classic Kaposi's sarcoma: clinicopathological study of five cases. Br J Dermatol 2001;145:847-9.

101. Cerimele D, Carlesimo F, Fadda G, et al. Anaplastic progression of classic Kaposi's sarcoma. Dermatology 1997:194:287-9.

102. Nayler SJ, Goetsch S, Grayson W, et al. Pleomorphic Kaposi's sarcoma: characterisation of an under-recognised variant of Kaposi's sarcoma. Mod Pathol 2000:13:13A.

103. Pantanowitz L, Dezube BJ, Pinkus GS, et al. Histological characterization of regression is acquired immunodeficiency syndrome-related Kaposi's sarcoma. J Cutan Pathol 2004;31:26-34.

104. Gasquet S, Maurin M, Brouqui $P$, et al. Bacillary angiomatosis in immunocompromised patients. AIDS 1998:12:1793-803.

105. Cockerell CJ, Tierno PM, Friedman-Kein AE, et al. Clinical, histologic, microbiologic and biochemical characterisation of the causative agent of bacillary (epithelioid) angiomatosis: a rickettsial illness with features of bartonellosis. J Invest Dermatol 1991; 97:812-7.

106. Amsbaugh S, Huiras E, Wang NS, et al. Bacillary angiomatosis associated with pseudoepitheliomatous hyperplasia. Am J Dermatopathol 2006;28:32-5.

107. Nayler SJ, Allard U, Taylor L, et al. HHV-8 (KSHV) is not associated with bacillary angiomatosis. Mod Pathol 1999:52:345-8.

108. Berger TG, Tappero JW, Kaymen A, et al. Bacillary (epithelioid) angiomatosis and concurrent Kaposi's sarcoma. Arch Dermatol 1989;125:1543-7.

109. Kanik AB, Hall JD, Bhawan J. Eruptive epithelioid haemangioendothelioma with spindle cells. Am J Dermatopathol 1995;17:612-7.

110. Pechere M, Chavaz P, Saurat JH. Multiple eruptive dermatofibromas in an AIDS patient: a new differential diagnosis of Kaposi's sarcoma. Dermatology 1995;190:319. 
111. Kanitakis J, Carbonnel E, Delmonte S, et al. Multiple eruptive dermatofibromas in a patient with HIV infection: case report and literature review. J Cutan Pathol 2000;27:54-6.

112. Kazakov DV, Prinz BM, Michaelis S, et al. Study of HHV-8 DNA sequences in archival biopsies from lesional skin of Kaposi's sarcoma, various mesenchymal tumors and related reactive conditions. J Cutan Pathol 2002;29:279-81.

113. Cheuk W, Wong KO, Wong CS, et al. Immunostaining for human herpesvirus 8 latent nuclear antigen-1 helps distinguish Kaposi sarcoma from its mimickers. Am J Clin Pathol 2004;121:335-42.

114. Castellano VM, Rodriguez-Peralto JL, Alonso S, et al. Dermatofibroma parasitized by Leishmania in HIV infection: a new morphologic expression of dermal kala azar in an immunodepressed patient. J Cutan Pathol 1999:26:516-9.

115. Forsyth SF, Lawn SD, Miller RF, et al. Multiple dermatofibroma-like lesions in a human immunodeficiency virus-positive patient coinfected with visceral leishmaniasis. Br J Dermatol 2003;148:185-7.

116. Beylot-Barry M, Vergier B, Masquelier B, et al. The spectrum of cutaneous lymphomas in HIV infection: a study of 21 cases. Am J Surg Pathol 1999;23:1208-16.

117. Janier M, Katlama C, Flaguel B, et al. The pseudo-Sézary syndrome with CD8 phenotype in a patient with the acquired immunodeficiency syndrome (AIDS). Ann Intern Med 1989:110:738-40.

118. Zhang $\mathbf{P}$, Chiriboga $\mathrm{L}$, Jacobson $\mathrm{M}$, et al. Mycosis fungoides like T-cell cutaneous lymphoid infiltrates in patients with HIV infection. Am J Dermatopathol 1995;17:29-35.

119. Bachelez H, Hadida F, Gorochov G. Massive infiltration of the skin by HIV-specific cytotoxic CD8+ cells. N Engl J Med 1996;335:61-2.

120. Guitart J, Variakojis D, Kuzel T, et al. Cutaneous CD8 T cell infiltrates in advanced HIV infection. J Am Acad Dermatol 1999:41:722-7.

121. Florell SR, Cessna M, Lundell RB, et al. Usefulness (or lack thereof) of immunophenotyping in atypical cutaneous T-cell infiltrates. Am J Clin Pathol 2006;125:727-36.

122. Colomo L, Loong F, Rives $\mathrm{S}$, et al. Diffuse large B-cell lymphomas with plasmablastic differentiation represent a heterogeneous group of disease entities. Am J Surg Pathol 2004;28:736-47.

123. Jordan LB, Lessells AM, Goodlad JR. Plasmablastic lymphoma arising at a cutaneous site. Histopathology 2005;46:108-17.

124. Gilaberte M, Gallardo F, Bellosillo B, et al. Recurrent and self-healing cutaneous monoclonal plasmablastic infiltrates in a patient with AIDS and Kaposi sarcoma. Br J Dermatol 2005:153:828-32.

125. Cochran REI, Thomson J, Fleming KA, et al. Histology simulating reticulosis in secondary syphilis. $\mathrm{Br} J$ Dermatol 1976;95:251-4.
126. Hodak E, David M, Rotham A, et al. Nodular secondary syphilis mimicking cutaneous lymphoreticular process. J Am Acad Dermatol 1987:17:914-7.

127. Fagan WA, Collins PC, Pulitzer DR. Verrucous herpes virus infection in patients with human immunodeficiency virus patients. Arch Pathol Lab Med 1996;120:956-8

128. Nikkels AF, Snoek R, Rentier B, et al. Chronic verrucous varicella zoster virus skin lesions: clinical, molecular and therapeutic aspects. Clin Exp Dermatol 1999;24:346-53.

129. Schlesinger I, Oerlich DM, Tyring SK. Crusted (Norwegian) scabies in patients with AIDS: the range of clinical presentations. South Med J 1994:87:352-6.

130. Smith KJ, Skelton HG III, James WD, et al. Neutrophilic eccrine hidradenitis in HIV infected patients. J Am Acad Dermatol 1990:23:945-7.

131. Morar N, Dlova N, Gupta AK, et al. Erythroderma: a comparison between HIV positive and negative patients. Int J Dermatol 1999;38:895-900.

132. Barlow RJ, Schulz EJ. Necrotizing folliculitis of AIDS. Br J Dermatol 1987;116:581-4

133. Dyall-Smith D, Masson G. Fungal eosinophilic pustular folliculitis. Australas J Dermatol 1995;36:37-8.

134. Rongioletti F, Ghigliotti G, De Marchi R, et al. Cutaneous mucinoses and HIV infection. Br J Dermatol 1998:139:1077-80.

135. Odom RB, James WD, Berger TG. Papular mucinosis and AIDS. In: Odom RB, James WD, Berger TG, eds. Andrews' diseases of the skin: clinical dermatology, 9th edn. Philadelphia: WB Saunders, 2000:207.

136. Daudén E, Peñas PF, Buezo GF, et al. Reticular erythematous mucinosis associated with human immunodeficiency virus infection. Dermatology 1995;157:157-60.

137. Kaplan MH, Sadik NS, McNutt MS, et al. Dermatologic findings and manifestations of acquired immunodeficiency syndrome (AIDS). J Am Acad Dermatol 1987;16:485-506.

138. Eisenstat B, Wormser GP. Seborrheic dermatitis and butterfly rash in AIDS. N Engl J Med 1984;311:358-64.

139. Weedon D. The granulomatous reaction pattern. In: Weedon D, ed. Skin pathology 2nd edn. Philadelphia: Churchill Livingstone, 2002:200-2.

140. Ruiz-Rodriguez R, Longaker M, Berger TG. Anetoderma and human immunodeficiency virus infection. Arch Dermatol 1992;128:661-2.

141. Mastrolorenzo A, Tiradritti L, Vichi F, et al. Primary anetoderma and HIV infection: a case report. AIDS Read 2006;16:92-6.

142. Lindstrom J, Smith KJ, Skelton HG, et al. Increased anticardiolipin antibodies associated with the development of anetoderma in HIV-1 disease. Military Medical Consortium for the Advancement of Retroviral Research (MMCARR). Int J Dermatol 1995; 34:408-15 